\title{
Peganum harmala and its Alkaloids as Dopamine Receptor Antagonists: in Silico Study
}

\author{
Mohammad Rizki Fadhil Pratama ${ }^{1 *}{ }^{*}$, Tohfa Aslan Nasibova ${ }^{2}$ (D), Dina Pratiwi ${ }^{3}$ (D) Punet Kumar $^{4(D)}$, \\ Eldar Abdulla Garaev 5 (D)
}

1 Department of Pharmacy, Universitas Muhammadiyah Palangkaraya, Palangka Raya, Central Kalimantan, Indonesia; m.rizkifadhil@umpalangkaraya.ac.id (M.R.F.P.);

2 Department of General and Toxicological Chemistry, Azerbaijan Medical University, A. Gasimzade 14, AZ1022, Baku, Azerbaijan; dr.tohfe@gmail.com (T.A.N.);

3 Department of Pharmacy, Sekolah Tinggi Farmasi Muhammadiyah Tangerang, Tangerang, Banten, Indonesia; dinapratiwi10@ymail.com (D.P.);

4 Department of Pharmaceutical Chemistry, Shri Gopichand College of Pharmacy, Harchandpur, Uttar Pradesh, India; punetkumar987@gmail.com (P.K.);

5 Department of General and Toxicological Chemistry, Azerbaijan Medical University, A. Gasimzade 14, AZ1022, Baku, Azerbaijan; eldargar@mail.ru (E.A.G.);

* Correspondence: m.rizkifadhil@umpalangkaraya.ac.id;

Scopus Author ID 56925239400

Received: 11.08.2020; Revised: 4.10.2020; Accepted: 8.10.2020; Published: 14.10.2020

Abstract: Peganum harmala is known to have active metabolites such as alkaloids, which can affect the central nervous system. One of the various alkaloids is thought to be related to their activity as dopamine receptor antagonists, which can be developed in the therapy of various neurological diseases. This study aims to determine the alkaloid from $P$. harmala, which has the highest potential as the dopamine receptor antagonist. The method used was molecular docking against dopamine receptors with risperidone as the reference ligand. The results showed that among the known alkaloids from $P$. harmala, dipegine, harmalanine, and harmalacinine showed the highest potency in terms of both free energy of binding and similarity of ligand-receptor interactions. The results of this investigation anticipate that some alkaloids from $P$. harmala have the potential as the dopamine receptor antagonist.

Keywords: Alkaloid; Docking; Dopamine receptor; Peganum harmala.

(C) 2020 by the authors. This article is an open-access article distributed under the terms and conditions of the Creative Commons Attribution (CC BY) license (https://creativecommons.org/licenses/by/4.0/).

\section{Introduction}

Peganum harmala L., which is also known as the Syrian rue or African rue, is a significant species of the family Nitrariaceae and is a perennial, wild-growing shrub that is mainly widespread in Asia, North Africa, and America [1]. Previously, this plant belonged to the family Zygophyllaceae, but later, as a result of phylogenetic studies on $P$. harmala, it was included in the family Nitrariaceae [2]. Along with this species, $P$. nigellastrum and $P$. multisectum are also found in Central Asia and China, while P. mexicanum is widespread in the Americas, especially in Mexico [3]. The appearance of the whole plant, flowers, and dried seeds of $\mathrm{P}$. harmala is presented in Figure 1.

Peganum harmala is more known for its alkaloid content, which is divided into two groups: $\beta$-carboline and quinazoline alkaloids. Previous studies by Li et al. [4] shows that among several alkaloids that were successfully isolated, harmine, harmaline, harmol, harmalol, harman, norharman, tetrahydroharmine, tetrahydroharmol, tetrahydroharman, 
tetrahydronorharman, isoharmine, harmalacidine, harmalidine, harmalicine, harmalanine, harmalacinine, ruine, dihydroruine are $\beta$-carboline alkaloids; while vasicine (peganine), 1 vasicinone, desoxypeganine, desoxyvasicinone, peganol, vasicol, pegamine, pegaline, peganidine, isopeganidine, dipegine, and dipeginol belong to quinazoline alkaloids. Due to the alkaloids contained in P. harmala, it is presented as a central nervous system (CNS)stimulating factor [5].

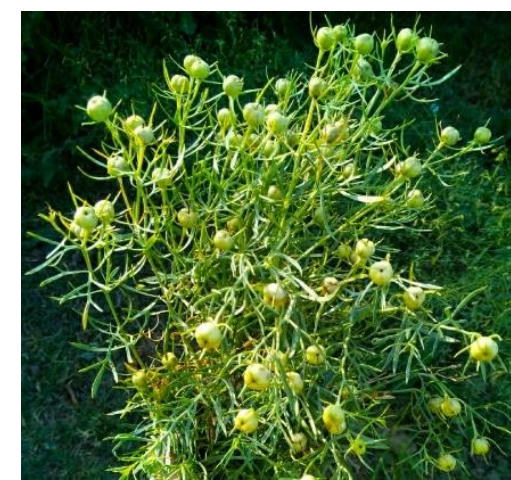

(a)

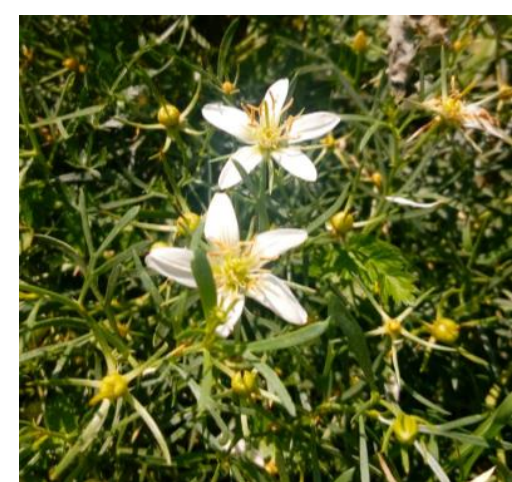

(b)

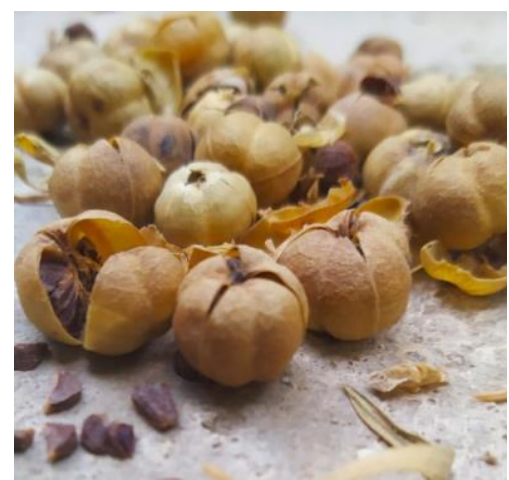

(c)

Figure 1. Peganum harmala plant; (a) whole plants; (b) the flowers; and (c) dried seeds.

Studies have been conducted on the neuroprotective, anti-paralytic, anxiolytic, anticonvulsant, analgesic effects of these alkaloids, and positive results have been obtained [4]. Even the German company Merck had produced anti-Alzheimer's drugs in the form of injection and suppository of harmine alkaloid, one of the main active ingredient of $P$. harmala [6]. It has also benefited from the positive effects of this plant on the nervous system in folk medicine. Peganum harmala seeds are used traditionally for antidepressant, sedative, analgesic purposes [7]. Occasionally, poisoning has been observed as a result of the overdose of seeds, which is accompanied by hallucinations and convulsions [8].

The dopamine receptor is an important target for the development of drugs for compounds that may affect the CNS [9]. Dopamine receptors are a class of G protein-coupled receptors that are prominent in the CNS of the vertebrates. Dopamine receptors activate different effectors not only by G-protein coupling but also by signaling different protein interactions [10]. Dopamine receptor disorders are believed to play a role in the development of multiple diseases such as Alzheimer's and Parkinson's, but the relationship is still under investigation [11-14]. Schizophrenia is one of the diseases known to be associated with dopamine receptor disorders [15]. The D2 dopamine receptor (DRD2), a subtype of dopamine receptors that specifically inhibits the production of cyclic adenosine monophosphate (cAMP) by inhibiting the enzyme adenyl cyclase, is the primary target for both typical and atypical antipsychotic medications and drugs used to treat schizophrenia-like risperidone $[16,17]$.

Considering how the alkaloids from $P$. harmala affect CNS in general, it is likely that one or several of these alkaloids can have activity on dopamine receptors, specifically as a DRD2 antagonist. However, to date, no research has been found that shows the relationship between the alkaloids of $P$. harmala and the dopamine receptor. Therefore, this study aims to determine the alkaloid from $P$. harmala, which has the highest potential as a DRD2 antagonist. The approach used is in silico with the molecular docking method, with the observed parameters are the free energy of binding $(\Delta \mathrm{G})$ and the similarity of ligand-receptor interactions, to be compared with risperidone as reference ligand. 


\section{Materials and Methods}

\subsection{Materials.}

The hardware used was the ASUS A46CB series Ultrabook with an Intel ${ }^{\mathrm{TM}}$ Core i53337U@1.8 GHz and Windows 7 Ultimate 64-bit SP-1 operating system. The software used was ChemDraw 18.0.0.231 and Chem3D 18.0.0.231 for molecular modeling and energy minimization, OpenBabel 2.4.1 for ligand and receptor format conversion, AutoDockTools 1.5.6 for docking protocol configuration, Autodock Vina 1.1.2 for the docking process, PyMOL 2.3.1 for docking protocol validation, UCSF Chimera 1.13.1 for the preparation of docking results, and Discovery Studio Visualizer 19.1.0.18287 for visualization and observation of docking results. Information on three-dimensional structures of receptor obtained from the website of Protein Data Bank http://www.rscb.org.

\subsection{Ligands preparation.}

The test ligands were consisted of 30 alkaloids from $P$. harmala, while the reference ligand was risperidone, as shown in Figure 2. The two-dimensional structure was sketched using ChemDraw 18.0.0.231, and its energy is minimized using Chem3D 18.0.0.231 with MMFF94. The format of the optimized structure was converted from *.mol to *.pdb using Open Babel 2.4.1. Then the charge of the ligands then is given the charge and set torque by default using AutoDockTools 1.5.6.<smiles>c1ccc2c(c1)CN1CCCC1=N2</smiles>

Desoxypeganine (1)<smiles>O=c1c2ccccc2nc2n1CCC2</smiles>

Desoxyvasicinone (2)<smiles>O=c1c2ccccc2nc2n1C(C1c3ccccc3N=C3CCCN31)CC2</smiles>

Dipegine (4)

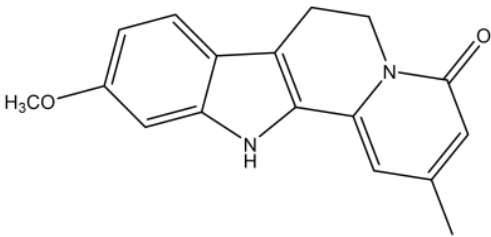

Harmalacinine (7)

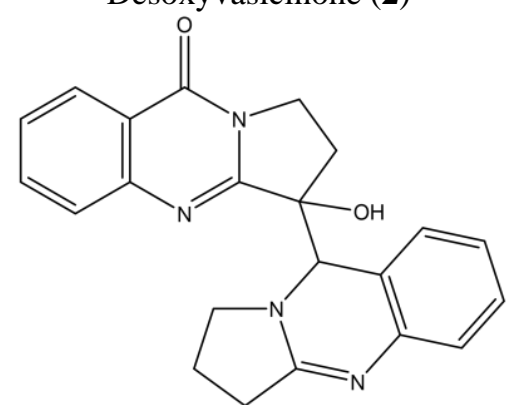

Dipeginol (5)

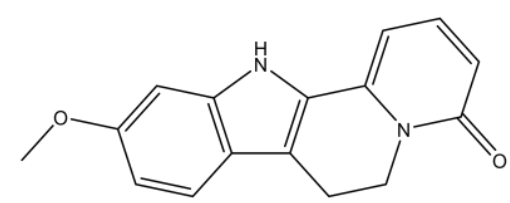

Harmalanine (8)

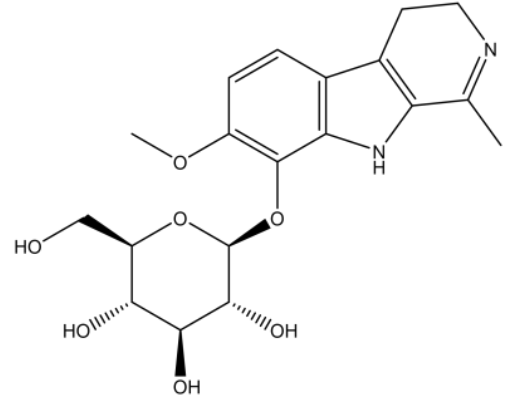

Dihidroruine (3)

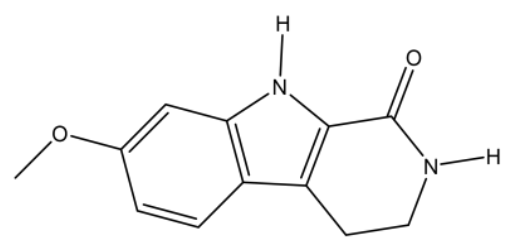

Harmalacidine (6)

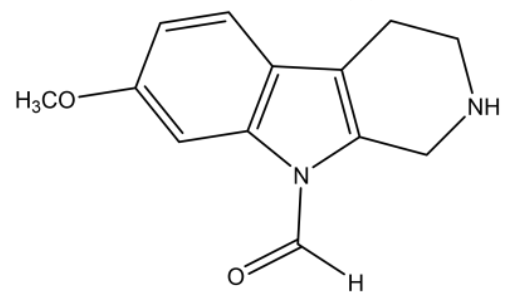

Harmalicine (9) 


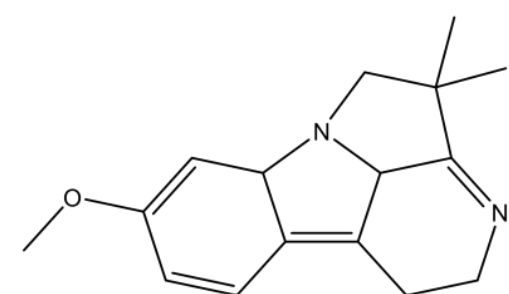

Harmalidine (10)

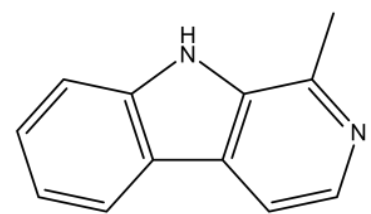

Harman (13)

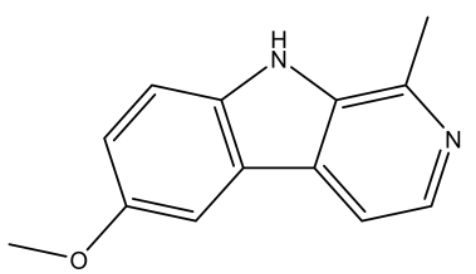

Isoharmine (16)<smiles>O=C(O)[C@@H]1C[C@@H](O)CCN1</smiles>

Pegaline (19)<smiles>OC1c2ccccc2N=C2CCCN21</smiles>

Peganol (22)<smiles>COc1ccc2c(c1)NC1C(C)NC=CC21</smiles>

Tetrahydroharmine (25)<smiles>O[C@@H]1CCN2Cc3ccccc3N=C12</smiles>

Vasicine (28)<smiles>COc1ccc2c3c([nH]c2c1)C(C)=NCC3</smiles>

Harmaline (11)<smiles>COc1ccc2c(c1)[nH]c1c(C)nccc12</smiles>

Harmine (14)<smiles>CC(=O)CC1c2ccccc2N=C2C(O)CCN21</smiles>

Isopeganidine (17)<smiles>O=c1[nH]c(CCCO)nc2ccccc12</smiles>

Pegamine (20)<smiles>COc1ccc2c([nH]c3c(C)nccc32)c1O[C@@H]1O[C@H](CO)[C@@H](O)[C@H](O)[C@H]1O</smiles>

Ruine (23)<smiles>CC1NC=CC2c3ccc(O)cc3NC12</smiles>

Tetrahydroharmol (26)<smiles>O=c1c2ccccc2nc2n1CC[C@H]2O</smiles>

Vasicinone (29)<smiles>CC1=NCCc2c1[nH]c1cc(O)ccc21</smiles>

Harmalol (12)<smiles>Cc1nccc2c1[nH]c1cc(O)ccc12</smiles>

Harmol (15)

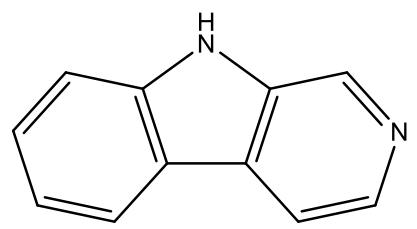

Norharman (18)<smiles>CC(=O)CC1c2ccccc2N=C2CCCN21</smiles>

Peganidine (21)

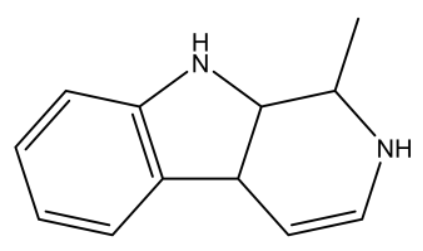

Tetrahydroharman (24)

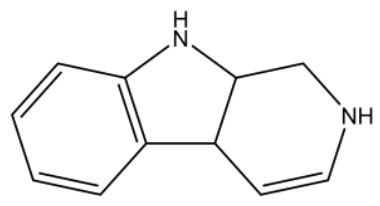

Tetrahydronorharman (27)<smiles>Nc1ccccc1CN1CC[C@H](O)C1=O</smiles>

Vasicol (30) 


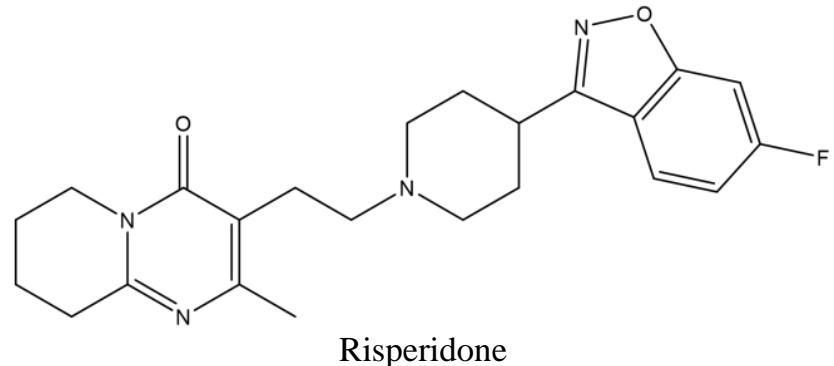

Figure 2. The two-dimensional structure of the test and reference ligands.

\subsection{Receptors preparation.}

The molecular structure of DRD2 in complexed with risperidone (PDB ID 6CM4) was obtained from the website of the protein data bank (PDB) http://www.rscb.org. The receptors are prepared for docking with AutoDock Vina 1.1.2 using the same protocol as reported by Pratama et al. [18]. The used structure of DRD2 is the active site that binds with risperidone as the reference ligand. Risperidone is known to be a dual DRD1-DRD2 family antagonist, with 70-fold selectivity for the DRD2 family [16].

\subsection{Validation of docking protocol.}

Before the docking process for test ligands, initially, the validation of the docking protocol is conducted. The redocking process is performed using the co-crystal ligands of the receptor. Risperidone from the receptor is extracted and prepared until a ligand in *.pdbqt format is obtained, according to the procedure reported by Pratama et al. [19]. The reference ligand was then redocked at the position of the grid box, and the size of the orientation result was predetermined. The orientation is performed in such a way as to achieve the smallest size grid box that can accommodate the entire ligand [20,21]. The parameters observed during the validation process are the root-mean-square deviation (RMSD) of the reference ligand at the selected binding site using PyMOL 2.3.1. The docking protocol is valid if an RMSD value of not more than $2 \AA$ is obtained [22].

\subsection{Molecular docking.}

Molecular docking for both tests and reference ligands conducted in the same way as the validation process with identical sizes and grid positions. Running for the docking process is performed by Autodock Vina 1.1.2. The key parameters used during the docking process with Autodock Vina were $\Delta \mathrm{G}$ and the similarity of ligand-receptor interactions [23-25]., The similarity in ligand-receptor interactions is measured by averaging the sum of the percentage in amino acid similarity to the percentage of similarity in the form of interaction that happens. The higher ligand-receptor interaction similarity suggests a higher chance that the ligand test will have a similar mechanism of action compared to co-crystal ligands [26]. The docking method is repeated five times, and the average score for $\Delta \mathrm{G}$ is used, while the standard deviation maximum values should not be higher than $0.2 \mathrm{kcal} / \mathrm{mol}$. Ligand-pose with the lowest $\Delta \mathrm{G}$ is then stored in *.pdb format using Chimera 1.13.1. The two-dimensional structure of the docking was analyzed using Discovery Studio Visualizer 19.1.0. 


\section{Results and Discussion}

\subsection{Validation of docking protocol.}

The RMSD value obtained from the redocking process of the 6CM4 receptor was 0.386 $\AA$. This indicates that the docking protocol for the receptor was valid for docking purposes. Figure 3 shows the visualization of ligand overlays from redocking with reference ligands from crystallographic results. A total of 23 amino acids are interacting with the 6CM4 receptor. Among the many types of interactions that exist, the majority (13 of 23) is dominated by van der Waals interactions, and only one hydrogen bond is formed at the serine residue number 197. In conclusion, the redocking process indicates that the docking protocol of the receptor can be used for the docking process. The parameters observed during the validation process are the $\Delta \mathrm{G}$ and amino acid interactions, as well as the size and coordinates of the grid box, as shown in Table 1.

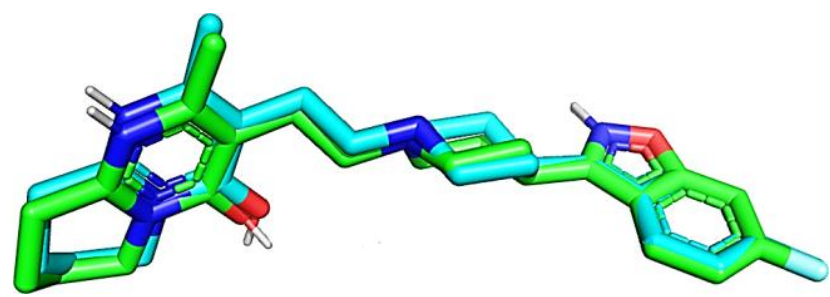

Figure 3. Overlays of redocking ligands (blue) with co-crystal ligands from X-crystallography data (green) at receptors 6CM4 with RMSD $0.386 \AA$.

Table 1. Results of the validation process.

\begin{tabular}{|c|c|}
\hline Parameters & Value \\
\hline PDB ID & $6 \mathrm{CM} 4$ \\
\hline Reference ligand & Risperidone \\
\hline Grid box size $(\AA)$ & $18 \times 28 \times 40$ \\
\hline Grid box position & $\begin{array}{l}\mathrm{x}: 9.812 \\
\mathrm{y}:-0.257 \\
\mathrm{z}: 20.406\end{array}$ \\
\hline RMSD $(\AA)$ & 0.386 \\
\hline$\Delta \mathrm{G}(\mathrm{kcal} / \mathrm{mol})$ & -11.92 \\
\hline \multirow[t]{23}{*}{ Amino acid residues } & $91-\mathrm{Val}^{\mathrm{a}}$ \\
\hline & 94-Leu ${ }^{\mathrm{a}}$ \\
\hline & $100-\operatorname{Trp}^{\mathrm{d}}$ \\
\hline & $110-$ Phe $^{\mathrm{a}}$ \\
\hline & $114-\mathrm{Asp}^{\mathrm{f}}$ \\
\hline & $115-\mathrm{Val}^{\mathrm{b}}$ \\
\hline & 118-Cys ${ }^{\mathrm{g}}$ \\
\hline & 119-Thr ${ }^{\mathrm{a}}$ \\
\hline & $122-$ Ala $^{\mathrm{a}}$ \\
\hline & $184-$ Ile $^{\mathrm{a}}$ \\
\hline & 189-Phe ${ }^{\mathrm{a}}$ \\
\hline & $193-$ Ser $^{\mathrm{a}}$ \\
\hline & $197-$ Ser $^{\mathrm{c}}$ \\
\hline & 198-Phe ${ }^{\mathrm{a}}$ \\
\hline & $382-$ Phe $^{\mathrm{a}}$ \\
\hline & 386-Trp ${ }^{\mathrm{d}}$ \\
\hline & 389-Phe ${ }^{\mathrm{b}}$ \\
\hline & $390-$ Phe $^{\mathrm{d}}$ \\
\hline & 393-His ${ }^{\mathrm{a}}$ \\
\hline & $408-\mathrm{Tyr}^{\mathrm{b}}$ \\
\hline & $409-$ Ser $^{\mathrm{a}}$ \\
\hline & 412-Thr ${ }^{\mathrm{e}}$ \\
\hline & $416-\mathrm{Tyr}^{\mathrm{a}}$ \\
\hline
\end{tabular}

a Van der Waals interaction; ${ }^{\text {b }}$ Alkyl/Pi-alkyl interaction; ${ }^{\mathrm{c}}$ Hydrogen bond; ${ }^{\mathrm{d}} \mathrm{Pi}-\mathrm{Pi}$ T-shaped/Pi-Pi Stacked/Amide-Pi stacked; e Pi-sigma; ${ }^{\mathrm{f}}$ Unfavorable Bump/Donor-donor; ${ }^{\mathrm{g}}$ Halogen 
The docking protocol is performed with AutoDock Vina default settings, with an energy range of 3 , exhaustiveness of 8 , and a number of modes 9 . These configurations will usually provide reproducible and consistent results, although it is not unusual to change a variety of parameters, such as increasing exhaustiveness to increase the accuracy of the tests. It is particularly important if there is no repetition of the docking process [27].

The RMSD value of the docking ligand was very small (less than $0.5 \AA$ ), suggesting a quite similar position and orientation of the atoms to the crystallographic data. Interestingly, although the $\Delta \mathrm{G}$ value obtained is relatively small, the interactions that occur appear to be dominated by weak interactions, such as van der Waals. This indicates that many key amino acids play a significant role in ligand affinity at the binding site of the 6CM4 receptor [28-30]. In particular, some of these key amino acids have high energy interactions, such as the halogen bond in cysteine 118 and the hydrogen bond in serine 197 [31].

\subsection{Molecular docking.}

The docking results showed a fairly wide difference in the $\Delta \mathrm{G}$ value of each test ligand. The majority of test ligands (22 out of 30 ) had $\Delta \mathrm{G}$ values between -7 and $-8.5 \AA$. Of course, compared to the risperidone, which has a $\Delta \mathrm{G}$ value of almost $-12 \AA$, this value is very different. However, certain ligands, such as dipegine (4), harmalanine (8), and harmalacinine (7), showed a difference between 1.62 and $2.28 \AA$, which was relatively low compared to other test ligands. Also, of the three test ligands, harmalanine (8) and harmalacinine (7) also displayed a high percentage similarity of ligand-receptor interaction to risperidone relative to other ligands, specifically above 50\%. While some other ligands, such as harmalacidine (6), harmaline (11), harmalol (12), and tetrahydroharmine (25), also displayed a percent similarity above $50 \%$, the $\Delta \mathrm{G}$ values of these ligands varied significantly from risperidone (more than $3.5 \AA$ ). The overall docking results of test ligands against the 6CM4 receptor are shown in Tables 2 to 4, whereas two-dimensional visualization of ligand-receptor interactions of risperidone, dipegine (4), harmalanine (8), and harmalacinine (7) is presented in Figures 4 to 7.

Table 2. Results of the docking of all test ligands at the binding site of 6CM4 receptor (1).

\begin{tabular}{|c|c|c|c|c|c|c|c|c|c|c|}
\hline Ligand & 1 & 2 & 3 & 4 & 5 & 6 & 7 & 8 & 9 & 10 \\
\hline $\begin{array}{c}\Delta \mathrm{G} \pm \mathrm{SD} \\
(\mathrm{kcal} / \mathrm{mol})\end{array}$ & $\begin{array}{c}-7.2 \pm \\
0 \\
\end{array}$ & $\begin{array}{c}-8.22 \pm \\
0.04\end{array}$ & $\begin{array}{c}-8.6 \pm \\
0\end{array}$ & $\begin{array}{c}-10.3 \pm \\
0\end{array}$ & $\begin{array}{c}-9.52 \pm \\
0.04\end{array}$ & $\begin{array}{c}-8.2 \pm \\
0\end{array}$ & $\begin{array}{c}-9.64 \pm \\
0.05\end{array}$ & $\begin{array}{c}-9.8 \pm \\
0 \\
\end{array}$ & $\begin{array}{c}-7.1 \pm \\
0 \\
\end{array}$ & $\begin{array}{c}-7.42 \pm \\
0.04\end{array}$ \\
\hline \multirow[t]{11}{*}{$\begin{array}{l}\text { Amino acid } \\
\text { residues }\end{array}$} & - & - & $\begin{array}{c}\text { 91- } \\
\text { Val }^{\mathrm{a}}\end{array}$ & $\begin{array}{c}91- \\
\text { Val }^{\mathrm{b}}\end{array}$ & $\begin{array}{c}91- \\
\mathrm{Val}^{\mathrm{a}}\end{array}$ & - & - & - & $\begin{array}{c}91- \\
\mathrm{Val}^{\mathrm{b}}\end{array}$ & $\begin{array}{c}91- \\
\mathrm{Val}^{\mathrm{b}}\end{array}$ \\
\hline & - & - & $\begin{array}{l}\text { 94- } \\
\text { Leu }^{\text {f }}\end{array}$ & $\begin{array}{c}\text { 94- } \\
\text { Leu }^{\mathrm{b}}\end{array}$ & $\begin{array}{l}\text { 94- } \\
\text { Leu }^{\mathrm{a}}\end{array}$ & - & - & - & $\begin{array}{c}\text { 94- } \\
\text { Leu }^{\mathrm{e}}\end{array}$ & $\begin{array}{c}\text { 94- } \\
\text { Leu }^{\mathrm{c}}\end{array}$ \\
\hline & - & - & $\begin{array}{c}95- \\
\text { Glu }^{\mathrm{c}}\end{array}$ & $\begin{array}{c}95- \\
\text { Glu }^{\mathrm{a}}\end{array}$ & - & - & - & - & $\begin{array}{c}\text { 95- } \\
\text { Glu }^{\mathrm{a}}\end{array}$ & $\begin{array}{c}95- \\
\text { Glu }^{\mathrm{g}}\end{array}$ \\
\hline & - & - & $\begin{array}{l}\text { 98- } \\
\text { Gly }^{\mathrm{a}}\end{array}$ & - & - & - & - & - & - & - \\
\hline & - & - & $\begin{array}{l}100- \\
\operatorname{Trp}^{\mathrm{d}}\end{array}$ & $\begin{array}{l}100- \\
\operatorname{Trp}^{\mathrm{b}}\end{array}$ & $\begin{array}{l}100- \\
\operatorname{Trp}^{c}\end{array}$ & & $\begin{array}{l}100- \\
\operatorname{Trp}^{\mathrm{a}}\end{array}$ & $\begin{array}{l}100- \\
\operatorname{Trp}^{\mathrm{a}}\end{array}$ & $\begin{array}{l}100- \\
\operatorname{Trp}^{\mathrm{d}}\end{array}$ & $\begin{array}{l}100- \\
\operatorname{Trp}^{\mathrm{b}}\end{array}$ \\
\hline & - & - & $\begin{array}{l}\text { 110- } \\
\text { Phe }^{a}\end{array}$ & - & - & - & - & - & $\begin{array}{l}\text { 110- } \\
\text { Phe }^{a}\end{array}$ & $\begin{array}{l}\text { 110- } \\
\text { Phe }^{a}\end{array}$ \\
\hline & $\begin{array}{l}114- \\
\text { Asp }^{g}\end{array}$ & $\begin{array}{l}114- \\
\text { Asp }^{g}\end{array}$ & $\begin{array}{l}114- \\
\mathrm{Asp}^{\mathrm{a}}\end{array}$ & $\begin{array}{l}\text { 114- } \\
\text { Asp }^{a}\end{array}$ & - & $\begin{array}{l}114- \\
\text { Asp }^{g}\end{array}$ & $\begin{array}{l}114- \\
\text { Asp }^{g}\end{array}$ & $\begin{array}{l}114- \\
\text { Asp }^{g}\end{array}$ & $\begin{array}{l}114- \\
\mathrm{Asp}^{\mathrm{c}}\end{array}$ & - \\
\hline & $\begin{array}{l}115- \\
\mathrm{Val}^{\mathrm{b}}\end{array}$ & $\begin{array}{l}115- \\
\mathrm{Val}^{\mathrm{b}}\end{array}$ & - & - & - & $\begin{array}{l}115- \\
\mathrm{Val}^{\mathrm{b}}\end{array}$ & $\begin{array}{l}115- \\
\mathrm{Val}^{\mathrm{a}}\end{array}$ & $\begin{array}{l}115- \\
\mathrm{Val}^{\mathrm{c}}\end{array}$ & - & - \\
\hline & - & $\begin{array}{l}118- \\
\text { Cys }^{b}\end{array}$ & - & - & - & $\begin{array}{l}118- \\
\text { Cys }^{b}\end{array}$ & $\begin{array}{l}118- \\
\text { Cys }^{\mathrm{c}}\end{array}$ & $\begin{array}{l}118- \\
\text { Cys }^{b}\end{array}$ & - & - \\
\hline & - & $\begin{array}{l}\text { 119- } \\
\text { Thr }^{\mathrm{c}}\end{array}$ & - & - & - & $\begin{array}{l}\text { 119- } \\
\text { Thr }^{\mathrm{a}}\end{array}$ & $\begin{array}{l}\text { 119- } \\
\text { Thr }^{\mathrm{a}}\end{array}$ & $\begin{array}{l}\text { 119- } \\
\text { Thr }^{\mathrm{a}}\end{array}$ & - & - \\
\hline & - & $\begin{array}{l}122- \\
\text { Ala }^{b}\end{array}$ & - & - & - & $\begin{array}{l}122- \\
\text { Ala }^{\mathrm{a}}\end{array}$ & $\begin{array}{l}122- \\
\text { Ala }^{\mathrm{a}}\end{array}$ & $\begin{array}{l}\text { 122- } \\
\text { Ala }^{\mathrm{a}}\end{array}$ & - & - \\
\hline
\end{tabular}




\begin{tabular}{|c|c|c|c|c|c|c|c|c|c|c|}
\hline Ligand & 1 & 2 & 3 & 4 & 5 & 6 & 7 & 8 & 9 & 10 \\
\hline & - & - & $\begin{array}{l}184- \\
\text { Ile }^{\mathrm{a}}\end{array}$ & $\begin{array}{l}184- \\
\mathrm{Ile}^{\mathrm{e}}\end{array}$ & $\begin{array}{l}184- \\
\text { Ile }^{\mathrm{a}}\end{array}$ & $\begin{array}{l}184- \\
\text { Ile }^{\mathrm{a}}\end{array}$ & $\begin{array}{l}184- \\
\mathrm{Ile}^{\mathrm{b}}\end{array}$ & $\begin{array}{l}184- \\
\text { Ile }^{\mathrm{a}}\end{array}$ & $\begin{array}{l}184- \\
\text { Ile }^{\mathrm{a}}\end{array}$ & $\begin{array}{l}184- \\
\text { Ile }^{\text {a }}\end{array}$ \\
\hline & - & $\begin{array}{l}\text { 189- } \\
\text { Phe }^{\mathrm{a}}\end{array}$ & - & $\begin{array}{l}\text { 189- } \\
\mathrm{Phe}^{\mathrm{a}}\end{array}$ & $\begin{array}{l}\text { 189- } \\
\text { Phe }^{\mathrm{a}}\end{array}$ & $\begin{array}{l}\text { 189- } \\
\text { Phe }^{\mathrm{a}}\end{array}$ & $\begin{array}{l}189- \\
P^{\text {b }}\end{array}$ & $\begin{array}{l}\text { 189- } \\
\mathrm{Phe}^{\mathrm{a}}\end{array}$ & - & - \\
\hline & - & - & - & $\begin{array}{l}190- \\
\text { Val }^{\text {a }}\end{array}$ & - & - & $\begin{array}{l}190- \\
\text { Val }^{b}\end{array}$ & - & - & - \\
\hline & - & $\begin{array}{l}\text { 193- } \\
\text { Ser }^{\mathrm{a}}\end{array}$ & - & - & - & $\begin{array}{l}\text { 193- } \\
\text { Ser }^{\mathrm{a}}\end{array}$ & $\begin{array}{l}\text { 193- } \\
\text { Ser }^{f}\end{array}$ & $\begin{array}{l}\text { 193- } \\
\text { Ser }^{\mathrm{a}}\end{array}$ & - & - \\
\hline & - & $\begin{array}{l}197- \\
\text { Ser }^{\mathrm{c}}\end{array}$ & - & - & - & $\begin{array}{l}197- \\
\text { Ser }^{\mathrm{c}}\end{array}$ & $\begin{array}{l}197- \\
\text { Ser }^{\mathrm{c}}\end{array}$ & $\begin{array}{l}197- \\
\text { Ser }^{\mathrm{c}}\end{array}$ & - & - \\
\hline & - & $\begin{array}{l}\text { 198- } \\
\text { Phe }^{\mathrm{b}}\end{array}$ & - & - & - & $\begin{array}{l}\text { 198- } \\
\text { Phe }^{\mathrm{a}}\end{array}$ & $\begin{array}{l}\text { 198- } \\
\text { Phe }^{\mathrm{a}}\end{array}$ & $\begin{array}{l}\text { 198- } \\
\text { Phe }^{\mathrm{a}}\end{array}$ & - & - \\
\hline & - & $\begin{array}{l}\text { 382- } \\
\text { Phe }^{\text {a }}\end{array}$ & - & - & - & $\begin{array}{l}\text { 382- } \\
\text { Phe }^{\text {a }}\end{array}$ & - & $\begin{array}{l}\text { 382- } \\
\text { Phe }^{\text {a }}\end{array}$ & - & - \\
\hline & $\begin{array}{l}386- \\
\text { Trpp }^{\mathrm{c}}\end{array}$ & $\begin{array}{l}\text { 386- } \\
\operatorname{Trp}^{\mathrm{c}}\end{array}$ & - & - & - & $\begin{array}{l}386- \\
\operatorname{Trp}^{\mathrm{d}}\end{array}$ & $\begin{array}{l}386- \\
\text { Trpp }^{\mathrm{d}}\end{array}$ & $\begin{array}{l}386- \\
\operatorname{Trp}^{\mathrm{c}}\end{array}$ & - & - \\
\hline & - & $\begin{array}{l}\text { 389- } \\
\text { Phe }^{\text {a }}\end{array}$ & $\begin{array}{l}\text { 389- } \\
\text { Phe }^{\mathrm{a}}\end{array}$ & $\begin{array}{l}\text { 389- } \\
\text { Phe }^{\text {d }}\end{array}$ & $\begin{array}{l}\text { 389- } \\
\text { Phe }^{\text {d }}\end{array}$ & $\begin{array}{l}\text { 389- } \\
\text { Phe }^{\text {a }}\end{array}$ & $\begin{array}{l}389- \\
\text { Phe }^{\text {d }}\end{array}$ & $\begin{array}{l}389- \\
\text { Phe }^{\mathrm{d}}\end{array}$ & $\begin{array}{l}\text { 389- } \\
\text { Phe }^{\mathrm{a}}\end{array}$ & - \\
\hline & - & $\begin{array}{l}\text { 390- } \\
\text { Phe }^{\mathrm{d}}\end{array}$ & - & - & - & $\begin{array}{l}\text { 390- } \\
\text { Phe }^{\mathrm{d}}\end{array}$ & $\begin{array}{l}\text { 390- } \\
\text { Phe }^{\text {d }}\end{array}$ & $\begin{array}{l}\text { 390- } \\
\text { Phe }^{\mathrm{d}}\end{array}$ & - & - \\
\hline & - & - & - & $\begin{array}{l}\text { 393- } \\
\text { His }^{\mathrm{a}}\end{array}$ & $\begin{array}{l}\text { 393- } \\
\text { His }^{\mathrm{c}}\end{array}$ & - & $\begin{array}{l}393- \\
\text { His }^{\mathrm{g}}\end{array}$ & - & - & - \\
\hline & - & - & $\begin{array}{l}\text { 405- } \\
\text { Pro }^{\mathrm{a}}\end{array}$ & - & - & - & - & - & - & - \\
\hline & - & - & $\begin{array}{l}408- \\
\text { Tyr }^{\mathrm{d}}\end{array}$ & $\begin{array}{l}408- \\
T^{6} r^{b}\end{array}$ & $\begin{array}{l}408- \\
T^{\text {T }}\end{array}$ & - & - & - & $\begin{array}{l}\text { 408- } \\
\text { Tyr }^{\mathrm{a}}\end{array}$ & - \\
\hline & - & - & $\begin{array}{l}409- \\
\text { Ser }^{\mathrm{c}}\end{array}$ & $\begin{array}{l}409- \\
\text { Ser }^{\mathrm{c}}\end{array}$ & $\begin{array}{l}409- \\
\text { Ser }^{\mathrm{a}}\end{array}$ & - & - & - & $\begin{array}{l}409- \\
\text { Ser }^{\mathrm{a}}\end{array}$ & $\begin{array}{l}\text { 409- } \\
\text { Ser }^{\mathrm{a}}\end{array}$ \\
\hline & - & - & $\begin{array}{l}\text { 412- } \\
\text { Thr }^{\mathrm{e}}\end{array}$ & $\begin{array}{l}\text { 412- } \\
\text { Thr }^{\mathrm{a}}\end{array}$ & $\begin{array}{l}\text { 412- } \\
\text { Thr }\end{array}$ & - & $\begin{array}{l}\text { 412- } \\
\text { Thr }^{\mathrm{a}}\end{array}$ & $\begin{array}{l}\text { 412- } \\
\text { Thr }^{\mathrm{a}}\end{array}$ & $\begin{array}{l}\text { 412- } \\
\text { Thr }\end{array}$ & $\begin{array}{l}\text { 412- } \\
\text { Thr }\end{array}$ \\
\hline & - & - & $\begin{array}{l}\text { 413- } \\
\text { Trp }^{\text {a }}\end{array}$ & $\begin{array}{l}\text { 413- } \\
\operatorname{Trp}^{\mathrm{d}}\end{array}$ & $\begin{array}{l}\text { 413- } \\
\text { Trp }^{b}\end{array}$ & - & - & - & $\begin{array}{l}\text { 413- } \\
\text { Trp }^{\mathrm{a}}\end{array}$ & $\begin{array}{l}\text { 413- } \\
\text { Trp }^{\mathrm{a}}\end{array}$ \\
\hline & - & - & $\begin{array}{l}416- \\
\mathrm{Tyr}^{\mathrm{c}}\end{array}$ & $\begin{array}{l}416- \\
\text { Tyr }^{\mathrm{a}}\end{array}$ & - & - & $\begin{array}{l}\text { 416- } \\
\text { Tyr }^{\mathrm{a}}\end{array}$ & - & $\begin{array}{l}416- \\
\mathrm{Tyr}^{\mathrm{c}}\end{array}$ & $\begin{array}{l}416- \\
\text { Tyr }^{\mathrm{a}}\end{array}$ \\
\hline $\begin{array}{c}\text { The similarity of } \\
\text { amino acids with } \\
\text { co-crystal ligand } \\
(\%)\end{array}$ & 13.04 & 56.52 & 47.83 & 52.17 & 43.48 & 60.87 & 73.91 & 69.57 & 47.83 & 34.78 \\
\hline $\begin{array}{l}\text { The similarity in } \\
\text { the type of } \\
\text { interaction with } \\
\text { co-crystal ligand } \\
(\%)\end{array}$ & 4.35 & 26.09 & 21.74 & 17.39 & 21.74 & 47.83 & 30.43 & 39.13 & 21.74 & 17.39 \\
\hline $\begin{array}{l}\text { The similarity of } \\
\text { ligand-receptor } \\
\text { interaction* }(\%)\end{array}$ & 8.7 & 41.3 & 34.78 & 34.78 & 32.61 & 54.35 & 52.17 & 54.35 & 34.78 & 26.09 \\
\hline
\end{tabular}

a Van der Waals interaction; ${ }^{\text {b }}$ Alkyl/Pi-alkyl interaction; ${ }^{\text {c }}$ Hydrogen bond; ${ }^{\text {d }}$ Pi-Pi T-shaped/Pi-Pi Stacked/Amide-Pi stacked;

${ }^{\mathrm{e}} \mathrm{Pi}$-sigma; ${ }_{\mathrm{f}}^{\mathrm{f}}$ Unfavorable Bump/Donor-donor; ${ }^{\mathrm{g}} \mathrm{Pi}$-cation/anion/attractive charge; ${ }^{*}$ (Similarity of amino acids + similarity in type of interaction)/2.

Table 3. Results of the docking of all test ligands at the binding site of the 6CM4 receptor (2).

\begin{tabular}{|c|c|c|c|c|c|c|c|c|c|c|}
\hline Ligand & 11 & 12 & 13 & 14 & 15 & 16 & 17 & 18 & 19 & 20 \\
\hline $\begin{array}{c}\Delta \mathrm{G} \pm \mathrm{SD} \\
(\mathrm{kcal} / \mathrm{mol})\end{array}$ & $\begin{array}{c}-7.9 \pm \\
0\end{array}$ & $\begin{array}{c}-7.7 \pm \\
0\end{array}$ & $\begin{array}{c}-8.0 \pm \\
0\end{array}$ & $\begin{array}{c}-7.7 \pm \\
0\end{array}$ & $\begin{array}{c}-7.7 \pm \\
0\end{array}$ & $\begin{array}{c}-8.1 \pm \\
0\end{array}$ & $\begin{array}{l}-6.94 \pm \\
0.05\end{array}$ & $\begin{array}{c}-8.2 \pm \\
0\end{array}$ & $\begin{array}{c}-5.6 \pm \\
0\end{array}$ & $\begin{array}{c}-7.8 \pm \\
0\end{array}$ \\
\hline \multirow[t]{6}{*}{$\begin{array}{l}\text { Amino acid } \\
\text { residues }\end{array}$} & - & - & - & - & - & - & $\begin{array}{c}91- \\
\mathrm{Val}^{\mathrm{b}}\end{array}$ & - & - & - \\
\hline & - & - & - & - & - & - & $\begin{array}{c}\text { 94- } \\
\text { Leu }^{\text {a }}\end{array}$ & - & - & - \\
\hline & - & - & - & - & - & - & $\begin{array}{l}\text { 100- } \\
\text { Trp }^{\mathrm{d}}\end{array}$ & - & - & - \\
\hline & - & - & - & - & - & - & $\begin{array}{l}110- \\
P^{a} e^{a}\end{array}$ & - & - & - \\
\hline & $\begin{array}{l}\text { 114- } \\
\text { Asp }\end{array}$ & $\begin{array}{l}\text { 114- } \\
\text { Asp }^{\mathrm{a}}\end{array}$ & $\begin{array}{l}\text { 114- } \\
\text { Asp }^{\mathrm{c}}\end{array}$ & $\begin{array}{l}\text { 114- } \\
\text { Asp }\end{array}$ & $\begin{array}{l}\text { 114- } \\
\text { Asp }\end{array}$ & $\begin{array}{l}\text { 114- } \\
\text { Asp }^{\mathrm{a}}\end{array}$ & $\begin{array}{l}\text { 114- } \\
\text { Asp }^{\mathrm{c}}\end{array}$ & $\begin{array}{l}\text { 114- } \\
\text { Asp }\end{array}$ & $\begin{array}{l}114- \\
\text { Asp }^{c}\end{array}$ & $\begin{array}{l}114- \\
\text { Asp }^{\mathrm{c}}\end{array}$ \\
\hline & $\begin{array}{l}115- \\
\mathrm{Val}^{\mathrm{a}}\end{array}$ & $\begin{array}{l}115- \\
\mathrm{Val}^{\mathrm{a}}\end{array}$ & $\begin{array}{l}115- \\
\text { Val }^{\mathrm{b}}\end{array}$ & $\begin{array}{l}115- \\
\mathrm{Val}^{\mathrm{a}}\end{array}$ & $\begin{array}{l}115- \\
\mathrm{Val}^{\mathrm{b}}\end{array}$ & $\begin{array}{l}115- \\
\mathrm{Val}^{\mathrm{a}}\end{array}$ & - & $\begin{array}{l}115- \\
\mathrm{Val}^{\mathrm{b}}\end{array}$ & $\begin{array}{l}115- \\
\mathrm{Val}^{\mathrm{a}}\end{array}$ & $\begin{array}{l}115- \\
\text { Val }^{\text {b }}\end{array}$ \\
\hline
\end{tabular}




\begin{tabular}{|c|c|c|c|c|c|c|c|c|c|c|}
\hline Ligand & 11 & 12 & 13 & 14 & 15 & 16 & 17 & 18 & 19 & 20 \\
\hline & $\begin{array}{l}118- \\
\text { Cys }^{\mathrm{b}}\end{array}$ & $\begin{array}{l}118- \\
\text { Cys }^{\mathrm{c}}\end{array}$ & $\begin{array}{l}118- \\
\text { Cys }^{b}\end{array}$ & $\begin{array}{l}118- \\
\text { Cys }^{\mathrm{c}} \\
\end{array}$ & $\begin{array}{l}118- \\
\text { Cys }^{\mathrm{c}}\end{array}$ & $\begin{array}{l}118- \\
\text { Cys }^{b}\end{array}$ & - & $\begin{array}{l}118- \\
\mathrm{Cys}^{\mathrm{c}}\end{array}$ & $\begin{array}{l}118- \\
\text { Cys }^{\mathrm{a}} \\
\end{array}$ & $\begin{array}{l}118- \\
\text { Cys }^{\mathrm{b}}\end{array}$ \\
\hline & $\begin{array}{l}\text { 119- } \\
\text { Thr }^{\mathrm{a}}\end{array}$ & $\begin{array}{l}\text { 119- } \\
\text { Thr }^{\mathrm{a}}\end{array}$ & - & - & - & - & - & $\begin{array}{l}\text { 119- } \\
\text { Thr }^{\mathrm{a}}\end{array}$ & $\begin{array}{l}\text { 119- } \\
\text { Thr }^{\mathrm{c}}\end{array}$ & $\begin{array}{l}\text { 119- } \\
\text { Thr }^{\mathrm{c}}\end{array}$ \\
\hline & - & $\begin{array}{l}122- \\
\mathrm{Ala}^{\mathrm{a}}\end{array}$ & $\begin{array}{l}122- \\
\text { Ala }^{a}\end{array}$ & - & $\begin{array}{l}122- \\
\text { Ala }^{a}\end{array}$ & - & - & $\begin{array}{l}122- \\
\mathrm{Ala}^{\mathrm{a}}\end{array}$ & $\begin{array}{l}122- \\
\mathrm{Ala}^{\mathrm{a}}\end{array}$ & $\begin{array}{l}122- \\
\mathrm{Ala}^{\mathrm{b}}\end{array}$ \\
\hline & $\begin{array}{l}184- \\
\text { Ile }^{\mathrm{a}}\end{array}$ & - & - & $\begin{array}{l}184- \\
\text { Ile }^{\mathrm{a}}\end{array}$ & - & $\begin{array}{l}184- \\
\text { Ile }^{\mathrm{a}}\end{array}$ & $\begin{array}{l}184- \\
\text { Ile }^{\mathrm{a}}\end{array}$ & - & - & - \\
\hline & $\begin{array}{l}\text { 189- } \\
\text { Phe }^{\mathrm{a}}\end{array}$ & $\begin{array}{l}\text { 189- } \\
\text { Phe }^{\mathrm{a}}\end{array}$ & $\begin{array}{l}\text { 189- } \\
\text { Phe }^{\mathrm{a}}\end{array}$ & $\begin{array}{l}\text { 189- } \\
\text { Phe }^{\mathrm{a}}\end{array}$ & $\begin{array}{l}\text { 189- } \\
\text { Phe }^{\mathrm{a}}\end{array}$ & $\begin{array}{l}\text { 189- } \\
\text { Phe }^{\mathrm{a}}\end{array}$ & $\begin{array}{l}\text { 189- } \\
\text { Phe }^{\mathrm{a}}\end{array}$ & $\begin{array}{l}\text { 189- } \\
\text { Phe }^{\mathrm{a}}\end{array}$ & - & $\begin{array}{l}\text { 189- } \\
\text { Phe }^{\mathrm{a}}\end{array}$ \\
\hline & $\begin{array}{l}\text { 193- } \\
\text { Ser }^{\mathrm{f}}\end{array}$ & $\begin{array}{l}193- \\
\text { Ser }^{\mathrm{a}}\end{array}$ & $\begin{array}{l}193- \\
\text { Ser }^{\mathrm{a}}\end{array}$ & $\begin{array}{l}193- \\
\text { Ser }^{f}\end{array}$ & $\begin{array}{l}193- \\
\text { Ser }^{\mathrm{a}}\end{array}$ & $\begin{array}{l}\text { 193- } \\
\text { Ser }^{\mathrm{f}}\end{array}$ & - & $\begin{array}{l}193- \\
\text { Ser }^{\mathrm{a}}\end{array}$ & $\begin{array}{l}193- \\
\text { Ser }^{\text {a }}\end{array}$ & $\begin{array}{l}193- \\
\text { Ser }^{\mathrm{a}}\end{array}$ \\
\hline & $\begin{array}{l}197- \\
\text { Ser }^{\mathrm{c}}\end{array}$ & $\begin{array}{l}197- \\
\text { Ser }^{\mathrm{a}}\end{array}$ & $\begin{array}{l}197- \\
\text { Ser }^{\mathrm{a}}\end{array}$ & $\begin{array}{l}197- \\
\text { Ser }^{\mathrm{c}}\end{array}$ & $\begin{array}{l}197- \\
\text { Ser }^{\mathrm{a}}\end{array}$ & $\begin{array}{l}197- \\
\text { Ser }^{\mathrm{a}}\end{array}$ & - & $\begin{array}{l}197- \\
\text { Ser }^{\mathrm{c}}\end{array}$ & $\begin{array}{l}197- \\
\text { Ser }^{c}\end{array}$ & $\begin{array}{l}197- \\
\text { Ser }^{\mathrm{c}}\end{array}$ \\
\hline & $\begin{array}{l}\text { 198- } \\
\text { Phe }^{\mathrm{a}}\end{array}$ & $\begin{array}{l}\text { 198- } \\
\text { Phe }^{\mathrm{a}}\end{array}$ & $\begin{array}{l}\text { 198- } \\
\text { Phe }^{\mathrm{a}}\end{array}$ & $\begin{array}{l}\text { 198- } \\
\text { Phe }^{\mathrm{a}}\end{array}$ & $\begin{array}{l}\text { 198- } \\
\text { Phe }^{\mathrm{a}}\end{array}$ & $\begin{array}{l}\text { 198- } \\
\text { Phe }^{\mathrm{a}}\end{array}$ & - & $\begin{array}{l}\text { 198- } \\
\text { Phe }^{\mathrm{d}}\end{array}$ & $\begin{array}{l}\text { 198- } \\
\text { Phe }^{\mathrm{a}}\end{array}$ & $\begin{array}{l}\text { 198- } \\
\text { Phe }^{\mathrm{a}}\end{array}$ \\
\hline & - & $\begin{array}{l}\text { 382- } \\
\text { Phe }^{\text {a }}\end{array}$ & $\begin{array}{l}\text { 382- } \\
\text { Phe }^{\text {a }}\end{array}$ & - & $\begin{array}{l}\text { 382- } \\
\text { Phe }^{\text {a }}\end{array}$ & $\begin{array}{l}\text { 382- } \\
\text { Phe }^{\mathrm{a}}\end{array}$ & - & $\begin{array}{l}\text { 382- } \\
\text { Phe }^{\text {a }}\end{array}$ & $\begin{array}{l}\text { 382- } \\
\text { Phe }^{\mathrm{a}}\end{array}$ & $\begin{array}{l}382- \\
P^{a} e^{a}\end{array}$ \\
\hline & $\begin{array}{l}386- \\
\operatorname{Trp}^{\mathrm{d}}\end{array}$ & $\begin{array}{l}386- \\
\operatorname{Trp}^{\mathrm{d}}\end{array}$ & $\begin{array}{l}386- \\
\operatorname{Trp}^{\mathrm{c}}\end{array}$ & $\begin{array}{l}386- \\
\operatorname{Trp}^{\mathrm{d}}\end{array}$ & $\begin{array}{l}386- \\
\operatorname{Trp}^{\mathrm{d}}\end{array}$ & $\begin{array}{l}386- \\
\text { Trp }^{\text {e }}\end{array}$ & - & $\begin{array}{l}386- \\
\text { Trp }^{\text {e }}\end{array}$ & $\begin{array}{l}386- \\
\text { Trp }^{\text {a }} \\
\end{array}$ & $\begin{array}{l}386- \\
\operatorname{Trp}^{\mathrm{c}}\end{array}$ \\
\hline & $\begin{array}{l}\text { 389- } \\
\text { Phe }^{\text {a }}\end{array}$ & $\begin{array}{l}\text { 389- } \\
\text { Phe }^{\mathrm{d}}\end{array}$ & $\begin{array}{l}\text { 389- } \\
\text { Phe }^{\mathrm{d}}\end{array}$ & $\begin{array}{l}\text { 389- } \\
\text { Phe }^{\mathrm{a}}\end{array}$ & $\begin{array}{l}\text { 389- } \\
\text { Phe }^{\mathrm{d}}\end{array}$ & $\begin{array}{l}\text { 389- } \\
\text { Phe }^{\mathrm{a}}\end{array}$ & $\begin{array}{l}\text { 389- } \\
\text { Phe }^{\mathrm{a}}\end{array}$ & $\begin{array}{l}\text { 389- } \\
\text { Phe }^{\mathrm{a}}\end{array}$ & - & $\begin{array}{l}\text { 389- } \\
\text { Phe }^{\text {a }}\end{array}$ \\
\hline & $\begin{array}{l}390- \\
\text { Phe }^{\mathrm{d}}\end{array}$ & $\begin{array}{l}390- \\
\text { Phe }^{\mathrm{d}}\end{array}$ & $\begin{array}{l}390- \\
\text { Phe }^{\mathrm{d}}\end{array}$ & $\begin{array}{l}390- \\
\text { Phe }^{\mathrm{d}}\end{array}$ & $\begin{array}{l}390- \\
\text { Phe }^{\mathrm{d}}\end{array}$ & $\begin{array}{l}390- \\
\text { Phe }^{\mathrm{d}}\end{array}$ & - & $\begin{array}{l}390- \\
\text { Phe }^{\mathrm{d}}\end{array}$ & $\begin{array}{l}\text { 390- } \\
\text { Phe }^{\mathrm{a}}\end{array}$ & $\begin{array}{l}390- \\
\text { Phe }^{\mathrm{d}}\end{array}$ \\
\hline & $\begin{array}{l}393- \\
\text { His }^{\text {a }} \\
\end{array}$ & - & - & $\begin{array}{l}393- \\
\text { His }^{\text {a }} \\
\end{array}$ & - & - & $\begin{array}{l}393- \\
\text { His }^{\text {a }} \\
\end{array}$ & - & - & - \\
\hline & - & - & - & - & - & - & $\begin{array}{l}408- \\
\text { Tyr }^{\mathrm{e}}\end{array}$ & - & - & - \\
\hline & - & - & - & - & - & - & $\begin{array}{l}409- \\
\text { Ser }^{\mathrm{a}} \\
\end{array}$ & - & - & - \\
\hline & $\begin{array}{l}\text { 412- } \\
\text { Thr }^{\text {a }}\end{array}$ & $\begin{array}{l}412- \\
\text { Thr }^{\text {a }}\end{array}$ & $\begin{array}{l}\text { 412- } \\
\text { Thr }^{\text {a }}\end{array}$ & $\begin{array}{l}412- \\
\text { Thr }^{\text {a }}\end{array}$ & $\begin{array}{l}\text { 412- } \\
\text { Thr }^{\text {a }}\end{array}$ & $\begin{array}{l}412- \\
\text { Thr }^{\mathrm{a}}\end{array}$ & $\begin{array}{l}412- \\
\text { Thr }^{\mathrm{e}}\end{array}$ & - & - & $\begin{array}{l}\text { 412- } \\
\text { Thr }^{\text {a }}\end{array}$ \\
\hline & $\begin{array}{l}416- \\
\text { Tyr }^{\mathrm{a}}\end{array}$ & $\begin{array}{l}416- \\
\text { Tyr }^{\mathrm{a}}\end{array}$ & $\begin{array}{l}416- \\
\text { Tyr }^{\mathrm{a}}\end{array}$ & $\begin{array}{l}416- \\
\text { Tyr }^{\mathrm{a}}\end{array}$ & $\begin{array}{l}416- \\
\text { Tyr }^{\mathrm{a}}\end{array}$ & $\begin{array}{l}416- \\
\text { Tyr }\end{array}$ & $\begin{array}{l}416- \\
\text { Tyr }^{\mathrm{a}}\end{array}$ & - & - & $\begin{array}{l}416- \\
\text { Tyr }^{\text {a }}\end{array}$ \\
\hline $\begin{array}{c}\text { The similarity of } \\
\text { amino acids with } \\
\text { co-crystal ligand } \\
(\%)\end{array}$ & 65.22 & 65.22 & 60.87 & 60.87 & 60.87 & 60.87 & 56.52 & 56.52 & 47.83 & 65.22 \\
\hline $\begin{array}{l}\text { The similarity in } \\
\text { the type of } \\
\text { interaction with } \\
\text { co-crystal ligand } \\
(\%)\end{array}$ & 39.13 & 39.13 & 34.78 & 34.78 & 39.13 & 26.09 & 39.13 & 34.78 & 21.74 & 34.78 \\
\hline $\begin{array}{l}\text { The similarity of } \\
\text { ligand-receptor } \\
\text { interaction* }(\%)\end{array}$ & 52.17 & 52.17 & 47.83 & 47.83 & 50 & 43.48 & 47.83 & 45.65 & 34.78 & 50 \\
\hline
\end{tabular}

a Van der Waals interaction; ${ }^{\mathrm{b}}$ Alkyl/Pi-alkyl interaction; ${ }^{\mathrm{c}}$ Hydrogen bond; ${ }^{\mathrm{d}} \mathrm{Pi}-\mathrm{Pi}$ T-shaped/Pi-Pi Stacked/Amide-Pi stacked;

${ }^{\mathrm{e}}$ Pi-sigma; ${ }_{\mathrm{f}}^{\mathrm{f}}$ Unfavorable Bump/Donor-donor; ${ }^{\mathrm{g}} \mathrm{Pi}$-cation/anion/attractive charge; * (Similarity of amino acids + similarity in type of interaction)/2.

Table 4. Results of the docking of all test ligands at the binding site of the 6CM4 receptor (3).

\begin{tabular}{|c|c|c|c|c|c|c|c|c|c|c|}
\hline Ligand & 21 & 22 & 23 & 24 & 25 & 26 & 27 & 28 & 29 & 30 \\
\hline $\begin{array}{c}\Delta \mathrm{G} \pm \mathrm{SD} \\
(\mathrm{kcal} / \mathrm{mol})\end{array}$ & $\begin{array}{c}-7.2 \pm \\
0 \\
\end{array}$ & $\begin{array}{c}-8.3 \pm \\
0\end{array}$ & $\begin{array}{c}-8.5 \pm \\
0 \\
\end{array}$ & $\begin{array}{c}-7.02 \pm \\
0.04\end{array}$ & $\begin{array}{c}-7.1 \pm \\
0 \\
\end{array}$ & $\begin{array}{c}-7.3 \pm \\
0 \\
\end{array}$ & $\begin{array}{c}-8.6 \pm \\
0 \\
\end{array}$ & $\begin{array}{c}-8.0 \pm \\
0 \\
\end{array}$ & $\begin{array}{c}-8.08 \pm \\
0.04 \\
\end{array}$ & $\begin{array}{c}-7.7 \pm \\
0.07 \\
\end{array}$ \\
\hline \multirow[t]{6}{*}{$\begin{array}{l}\text { Amino acid } \\
\text { residues }\end{array}$} & - & - & $\begin{array}{c}41- \\
\mathrm{Leu}^{\mathrm{a}}\end{array}$ & - & - & - & - & - & - & - \\
\hline & $\begin{array}{c}\text { 91- } \\
\mathrm{Val}^{\mathrm{a}}\end{array}$ & - & $\begin{array}{c}\text { 91- } \\
\mathrm{Val}^{\mathrm{c}}\end{array}$ & - & - & $\begin{array}{c}91- \\
\text { Val }^{\mathrm{a}}\end{array}$ & - & - & - & - \\
\hline & $\begin{array}{c}\text { 94- } \\
\text { Leu }^{\mathrm{a}}\end{array}$ & - & $\begin{array}{c}\text { 94- } \\
\text { Leu }^{\mathrm{a}}\end{array}$ & - & - & $\begin{array}{c}\text { 94- } \\
\mathrm{Leu}^{\mathrm{e}}\end{array}$ & - & - & - & - \\
\hline & $\begin{array}{c}\text { 95- } \\
\text { Glu }^{\mathrm{a}}\end{array}$ & - & $\begin{array}{l}95- \\
\text { Glu }^{\mathrm{c}}\end{array}$ & - & - & $\begin{array}{l}95- \\
\text { Glu }^{\mathrm{c}}\end{array}$ & - & - & - & - \\
\hline & - & - & $\begin{array}{c}\text { 98- } \\
\text { Gly }^{\mathrm{a}}\end{array}$ & - & - & - & - & - & - & - \\
\hline & $\begin{array}{l}100- \\
\operatorname{Trp}^{b}\end{array}$ & - & $\begin{array}{l}100- \\
\operatorname{Trp}^{\mathrm{a}}\end{array}$ & - & - & $\begin{array}{l}100- \\
\operatorname{Trp}^{a}\end{array}$ & - & - & - & - \\
\hline
\end{tabular}




\begin{tabular}{|c|c|c|c|c|c|c|c|c|c|c|}
\hline Ligand & 21 & 22 & 23 & 24 & 25 & 26 & 27 & 28 & 29 & 30 \\
\hline & $\begin{array}{l}\text { 110- } \\
\text { Phe }^{\mathrm{a}}\end{array}$ & - & $\begin{array}{l}\text { 110- } \\
\text { Phe }^{\mathrm{a}}\end{array}$ & - & - & $\begin{array}{l}\text { 110- } \\
\text { Phe }^{\mathrm{a}}\end{array}$ & - & - & - & - \\
\hline & - & $\begin{array}{l}114- \\
\text { Asp }^{\text {a }}\end{array}$ & $\begin{array}{l}114- \\
\text { Asp }^{\mathrm{a}}\end{array}$ & $\begin{array}{l}114- \\
\text { Asp }^{\text {a }}\end{array}$ & $\begin{array}{l}114- \\
\text { Asp }^{c}\end{array}$ & - & - & $\begin{array}{l}114- \\
\text { Asp }\end{array}$ & $\begin{array}{l}114- \\
\text { Asp }\end{array}$ & $\begin{array}{l}114- \\
\text { Asp }^{\mathrm{c}}\end{array}$ \\
\hline & - & $\begin{array}{l}115- \\
\mathrm{Val}^{\mathrm{b}}\end{array}$ & - & $\begin{array}{l}115- \\
\mathrm{Val}^{\mathrm{a}}\end{array}$ & $\begin{array}{l}115- \\
\mathrm{Val}^{\mathrm{a}}\end{array}$ & - & $\begin{array}{l}115- \\
\mathrm{Val}^{\mathrm{a}}\end{array}$ & $\begin{array}{l}115- \\
\mathrm{Val}^{\mathrm{b}}\end{array}$ & $\begin{array}{l}115- \\
\mathrm{Val}^{\mathrm{b}}\end{array}$ & $\begin{array}{l}115- \\
\mathrm{Val}^{\mathrm{b}}\end{array}$ \\
\hline & - & $\begin{array}{l}118- \\
\text { Cys }\end{array}$ & - & $\begin{array}{l}118- \\
\text { Cys }^{b}\end{array}$ & $\begin{array}{l}118- \\
\text { Cys }\end{array}$ & - & $\begin{array}{l}118- \\
\text { Cys }^{b}\end{array}$ & $\begin{array}{l}118- \\
\text { Cys }\end{array}$ & $\begin{array}{l}118- \\
\text { Cys }\end{array}$ & $\begin{array}{l}118- \\
\mathrm{Cys}^{\mathrm{c}}\end{array}$ \\
\hline & - & $\begin{array}{l}\text { 119- } \\
\text { Thr }^{\text {a }}\end{array}$ & - & - & $\begin{array}{l}\text { 119- } \\
\text { Thr }^{\text {a }}\end{array}$ & - & $\begin{array}{l}\text { 119- } \\
\text { Thr }^{\mathrm{a}}\end{array}$ & $\begin{array}{l}\text { 119- } \\
\text { Thr }^{\mathrm{a}}\end{array}$ & $\begin{array}{l}\text { 119- } \\
\text { Thr }^{\mathrm{a}}\end{array}$ & $\begin{array}{l}\text { 119- } \\
\text { Thr }^{\mathrm{c}}\end{array}$ \\
\hline & - & 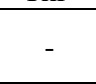 & - & - & - & - & - & $\begin{array}{l}121- \\
\text { Ser }^{\mathrm{a}}\end{array}$ & - & - \\
\hline & - & $\begin{array}{l}122- \\
\text { Ala }^{\mathrm{a}}\end{array}$ & - & - & $\begin{array}{l}122- \\
\mathrm{Ala}^{\mathrm{a}}\end{array}$ & - & $\begin{array}{l}122- \\
\mathrm{Ala}^{\mathrm{b}}\end{array}$ & $\begin{array}{l}122- \\
\text { Ala }^{\mathrm{a}}\end{array}$ & $\begin{array}{l}122- \\
\text { Ala }^{\mathrm{a}}\end{array}$ & $\begin{array}{l}122- \\
\mathrm{Ala}^{\mathrm{a}}\end{array}$ \\
\hline & $\begin{array}{l}\text { 184- } \\
\text { Ile }^{\mathrm{a}}\end{array}$ & - & - & - & - & - & - & - & - & - \\
\hline & - & $\begin{array}{l}\text { 189- } \\
\text { Phe }\end{array}$ & - & $\begin{array}{l}\text { 189- } \\
\text { Phe }^{a}\end{array}$ & $\begin{array}{l}\text { 189- } \\
\text { Phe }^{a}\end{array}$ & - & $\begin{array}{l}\text { 189- } \\
\text { Phe }\end{array}$ & $\begin{array}{l}\text { 189- } \\
\text { Phe }\end{array}$ & $\begin{array}{l}\text { 189- } \\
\text { Phe }\end{array}$ & $\begin{array}{l}\text { 189- } \\
\text { Phe }^{\text {a }}\end{array}$ \\
\hline & - & $\begin{array}{l}193- \\
\text { Ser }^{\mathrm{c}}\end{array}$ & - & $\begin{array}{l}193- \\
\text { Ser }^{\text {a }} \\
\end{array}$ & $\begin{array}{l}193- \\
\text { Ser }^{\text {a }} \\
\end{array}$ & - & $\begin{array}{l}193- \\
\text { Ser }^{\mathrm{f}}\end{array}$ & $\begin{array}{l}193- \\
\text { Ser }^{\text {a }} \\
\end{array}$ & $\begin{array}{l}193- \\
\text { Ser }^{\text {a }} \\
\end{array}$ & $\begin{array}{l}193- \\
\text { Ser }^{\mathrm{a}}\end{array}$ \\
\hline & - & $\begin{array}{l}\text { 197- } \\
\text { Ser }^{\text {a }}\end{array}$ & - & $\begin{array}{l}\text { 197- } \\
\text { Ser }^{\text {a }}\end{array}$ & $\begin{array}{l}197- \\
\text { Ser }^{\mathrm{a}}\end{array}$ & - & $\begin{array}{l}197- \\
\text { Ser }^{\mathrm{a}}\end{array}$ & - & $\begin{array}{l}197- \\
\text { Ser }^{\mathrm{c}}\end{array}$ & $\begin{array}{l}197- \\
\text { Ser }^{\mathrm{a}}\end{array}$ \\
\hline & - & $\begin{array}{l}\text { 198- } \\
\text { Phe }^{\mathrm{a}}\end{array}$ & - & $\begin{array}{l}\text { 198- } \\
\text { Phe }^{\mathrm{a}}\end{array}$ & $\begin{array}{l}\text { 198- } \\
\text { Phe }^{\mathrm{a}}\end{array}$ & - & $\begin{array}{l}\text { 198- } \\
\text { Phe }^{\mathrm{a}}\end{array}$ & $\begin{array}{l}\text { 198- } \\
\text { Phe }^{\text {a }}\end{array}$ & $\begin{array}{l}\text { 198- } \\
\text { Phe }^{\mathrm{a}}\end{array}$ & $\begin{array}{l}\text { 198- } \\
\text { Phe }^{\text {a }}\end{array}$ \\
\hline & - & $\begin{array}{l}382- \\
\text { Phe }^{\text {a }}\end{array}$ & - & $\begin{array}{l}382- \\
\text { Phe }^{\text {a }}\end{array}$ & $\begin{array}{l}382- \\
\text { Phe }^{\text {a }}\end{array}$ & - & $\begin{array}{l}382- \\
\text { Phe }^{\text {a }}\end{array}$ & $\begin{array}{l}382- \\
\text { Phe }^{\text {a }}\end{array}$ & $\begin{array}{l}382- \\
\text { Phe }^{\text {a }}\end{array}$ & $\begin{array}{l}382- \\
P^{a}{ }^{a}\end{array}$ \\
\hline & - & $\begin{array}{l}386- \\
\text { Trp }^{\mathrm{d}}\end{array}$ & - & $\begin{array}{l}386- \\
\operatorname{Trp}^{\mathrm{d}}\end{array}$ & $\begin{array}{l}386- \\
\text { Trp }^{\mathrm{d}}\end{array}$ & - & $\begin{array}{l}386- \\
\operatorname{Trp}^{d}\end{array}$ & $\begin{array}{l}386- \\
\operatorname{Trp}^{\mathrm{c}}\end{array}$ & $\begin{array}{l}386- \\
\text { Trp }^{\mathrm{c}}\end{array}$ & $\begin{array}{l}386- \\
\operatorname{Trp}^{\text {a }}\end{array}$ \\
\hline & $\begin{array}{l}\text { 389- } \\
\text { Phe }^{\mathrm{a}}\end{array}$ & $\begin{array}{l}389- \\
\text { Phe }^{\mathrm{b}}\end{array}$ & $\begin{array}{l}\text { 389- } \\
\text { Phe }^{\mathrm{a}}\end{array}$ & $\begin{array}{l}389- \\
\text { Phe }^{\text {a }}\end{array}$ & $\begin{array}{l}389- \\
\text { Phe }^{\text {a }}\end{array}$ & - & $\begin{array}{l}389- \\
P^{a} e^{a}\end{array}$ & $\begin{array}{l}389- \\
P^{a} e^{a}\end{array}$ & $\begin{array}{l}389- \\
\text { Phe }^{\mathrm{a}}\end{array}$ & $\begin{array}{l}389- \\
P^{a} e^{a}\end{array}$ \\
\hline & - & $\begin{array}{l}390- \\
\text { Phe }^{\mathrm{d}}\end{array}$ & - & $\begin{array}{l}390- \\
\text { Phe }^{\mathrm{d}}\end{array}$ & $\begin{array}{l}390- \\
\text { Phe }^{\mathrm{d}}\end{array}$ & - & $\begin{array}{l}390- \\
\text { Phe }^{\mathrm{a}}\end{array}$ & $\begin{array}{l}390- \\
\text { Phe }^{\mathrm{d}}\end{array}$ & $\begin{array}{l}390- \\
\text { Phe }^{\mathrm{d}}\end{array}$ & $\begin{array}{l}390- \\
\text { Phe }^{\text {a }}\end{array}$ \\
\hline & - & - & - & - & - & - & - & - & - & $\begin{array}{l}\text { 393- } \\
\text { His }^{\mathrm{a}}\end{array}$ \\
\hline & - & - & $\begin{array}{l}405- \\
\text { Pro }^{a}\end{array}$ & - & - & - & - & - & - & - \\
\hline & $\begin{array}{l}408- \\
\text { Tyr }\end{array}$ & - & $\begin{array}{l}408- \\
\text { Tyr }^{\mathrm{d}}\end{array}$ & - & - & - & - & - & - & - \\
\hline & $\begin{array}{l}409- \\
\text { Ser }^{\mathrm{a}}\end{array}$ & - & $\begin{array}{l}409- \\
\text { Ser }^{\mathrm{c}}\end{array}$ & - & - & $\begin{array}{l}409- \\
\text { Ser }^{\mathrm{a}}\end{array}$ & - & - & - & - \\
\hline & $\begin{array}{l}\text { 412- } \\
\text { Thr }^{\mathrm{e}}\end{array}$ & - & $\begin{array}{l}\text { 412- } \\
\text { Thr }^{\mathrm{a}}\end{array}$ & - & $\begin{array}{l}\text { 412- } \\
\text { Thr }^{\mathrm{a}}\end{array}$ & $\begin{array}{l}\text { 412- } \\
\text { Thr }^{\mathrm{a}}\end{array}$ & - & - & - & - \\
\hline & $\begin{array}{l}413- \\
\text { Trp }\end{array}$ & - & $\begin{array}{l}413- \\
\text { Trp }^{\text {a }}\end{array}$ & - & - & $\begin{array}{l}413- \\
\operatorname{Trp}^{\mathrm{d}}\end{array}$ & - & - & - & - \\
\hline & $\begin{array}{l}416- \\
\text { Tyr }^{\mathrm{a}}\end{array}$ & - & $\begin{array}{l}416- \\
\mathrm{Tyr}^{\mathrm{c}}\end{array}$ & - & $\begin{array}{l}416- \\
\text { Tyr }^{\mathrm{a}}\end{array}$ & $\begin{array}{l}416- \\
\mathrm{Tyr}^{\mathrm{c}}\end{array}$ & - & - & - & $\begin{array}{l}416- \\
\text { Tyr }^{\mathrm{a}}\end{array}$ \\
\hline $\begin{array}{l}\text { The similarity of } \\
\text { amino acids with } \\
\text { co-crystal ligand } \\
(\%)\end{array}$ & 43.48 & 56.52 & 43.48 & 47.83 & 65.22 & 30.43 & 52.17 & 52.17 & 56.52 & 65.22 \\
\hline $\begin{array}{l}\text { The similarity in } \\
\text { the type of } \\
\text { interaction with } \\
\text { co-crystal ligand } \\
(\%)\end{array}$ & 34.78 & 39.13 & 8.7 & 26.09 & 39.13 & 13.04 & 21.74 & 34.78 & 39.13 & 34.78 \\
\hline $\begin{array}{l}\text { The similarity of } \\
\text { ligand-receptor } \\
\text { interaction* }(\%)\end{array}$ & 39.13 & 47.83 & 26.09 & 36.96 & 52.17 & 21.74 & 36.96 & 43.48 & 47.83 & 50 \\
\hline
\end{tabular}

a Van der Waals interaction; ${ }^{\text {b }}$ Alkyl/Pi-alkyl interaction; ${ }^{\text {c }}$ Hydrogen bond; ${ }^{\text {d }}$ Pi-Pi T-shaped/Pi-Pi Stacked/Amide-Pi stacked; ${ }^{\mathrm{e}} \mathrm{Pi}$-sigma; ${ }_{\mathrm{f}}^{\mathrm{f}}$ Unfavorable Bump/Donor-donor; ${ }_{\mathrm{g}}^{\mathrm{P}} \mathrm{P}$-cation/anion/attractive charge; ${ }^{*}$ (Similarity of amino acids + similarity in type of interaction)/2 


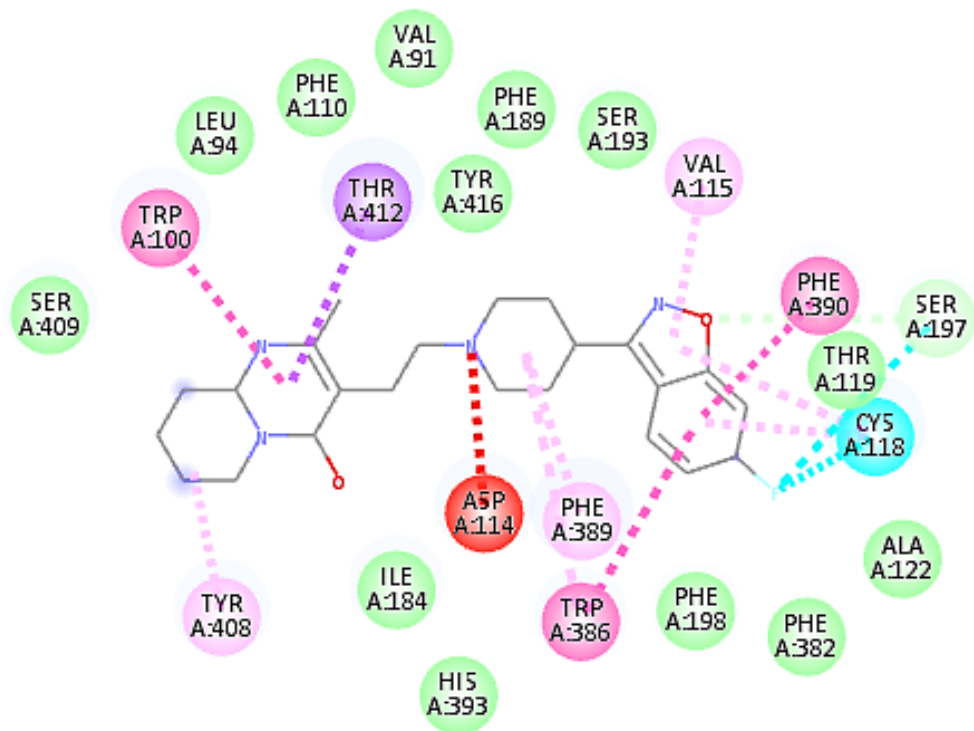

Figure 4. Interactions of risperidone in amino acid residues from the 6CM4 receptor.

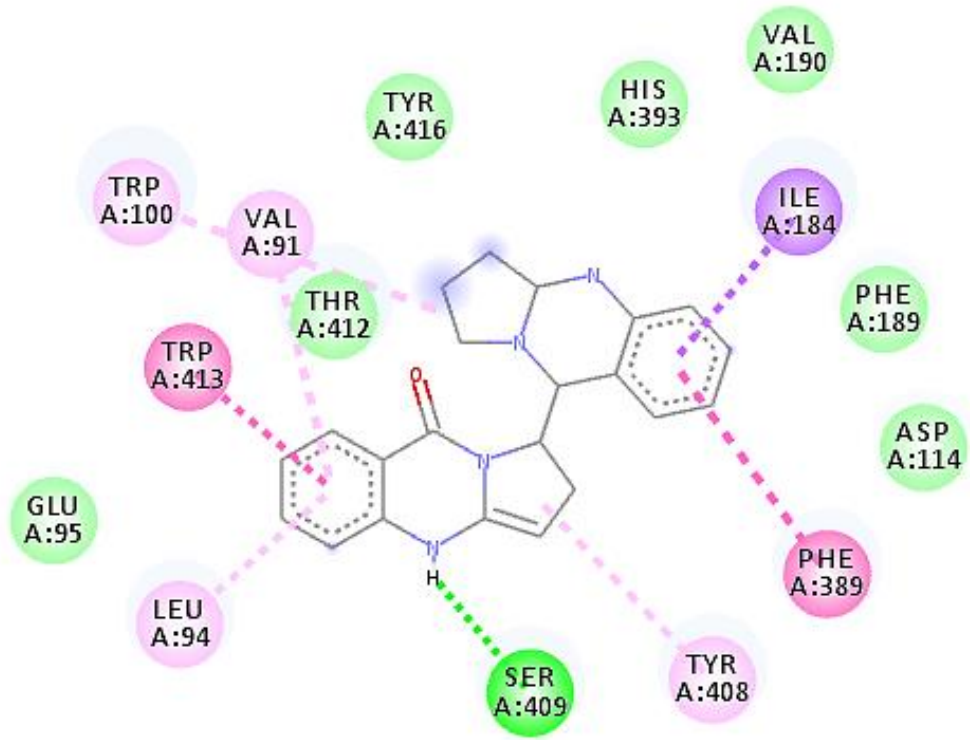

Figure 5. Interactions of dipegine (4) in amino acid residues from the 6CM4 receptor.

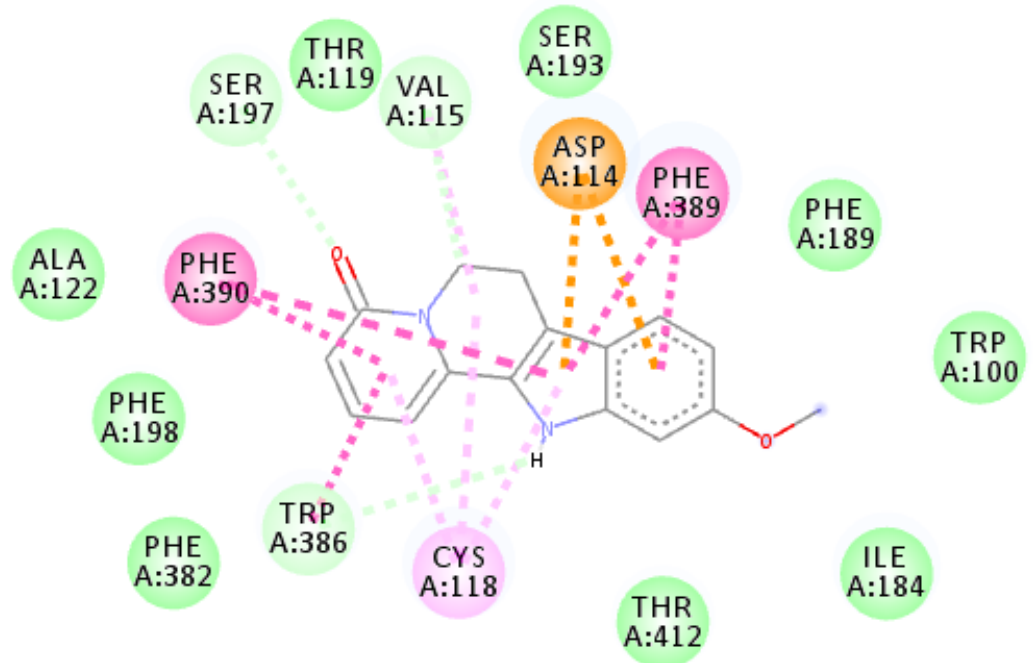

Figure 6. Interactions of harmalanine (8) in amino acid residues from the 6CM4 receptor. 


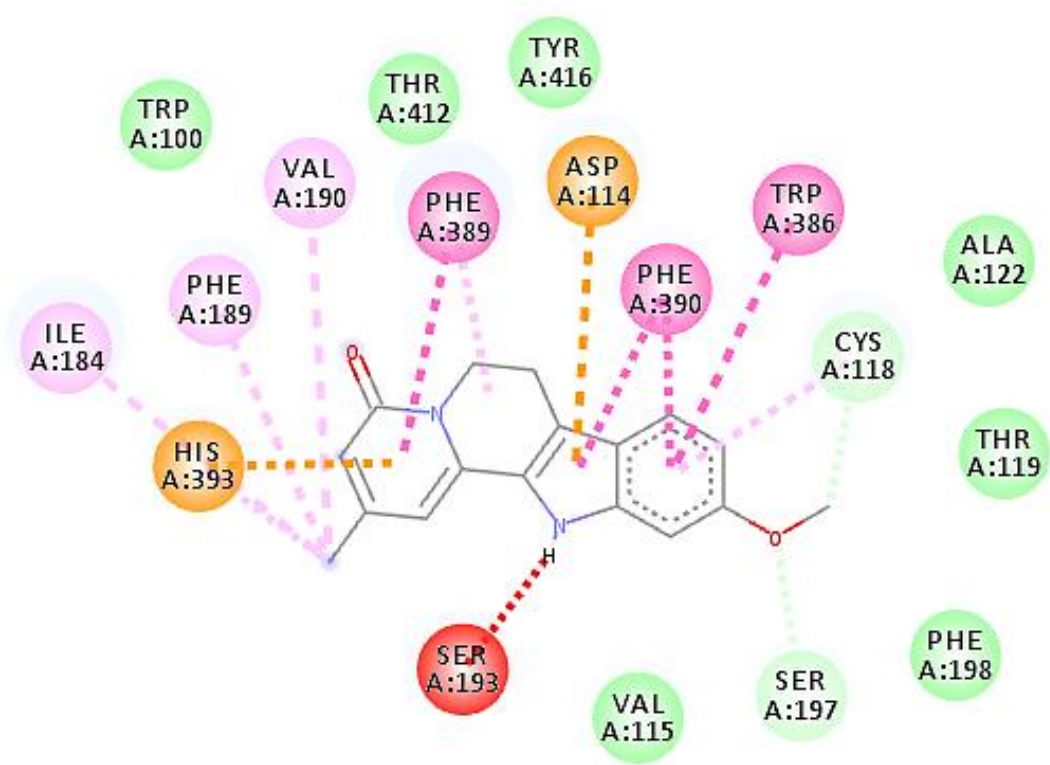

Figure 7. Interactions of harmalacinine (7) in amino acid residues from the 6CM4 receptor.

To aid the comparison of $\Delta \mathrm{G}$ values and the $\%$ similarity of all test and reference ligands on the two receptors, a scatter diagram was created, as displayed in Figure 8. The diagram contrasts the difference in $\Delta \mathrm{G}$ value between test and reference ligands with the $\%$ similarity of ligand-receptor interaction, where the line 0 on the $\mathrm{x}$-axis represents the position of the reference crystal ligand at the receptor. The area to the left of the 0 line shows a negative value, which means that the $\Delta \mathrm{G}$ value of the ligand is lower than the reference ligand, and vice versa. While on the y-axis, it shows the \% similarity of ligand-receptor interaction compared to reference ligand at the receptor. The further to the left and the higher the ligand position in the diagram, the stronger probability that the ligand has the potential to be a receptor inhibitor. In Figure 8 , it appears that all test ligands are in the right area of the diagram. However, the diagram shows that dipegine (4), harmalanine (8), and harmalacinine (7) are predominantly in the upper left area of the diagram, confirms the prediction that all three have the best potential as DRD2 antagonists among other test ligands.

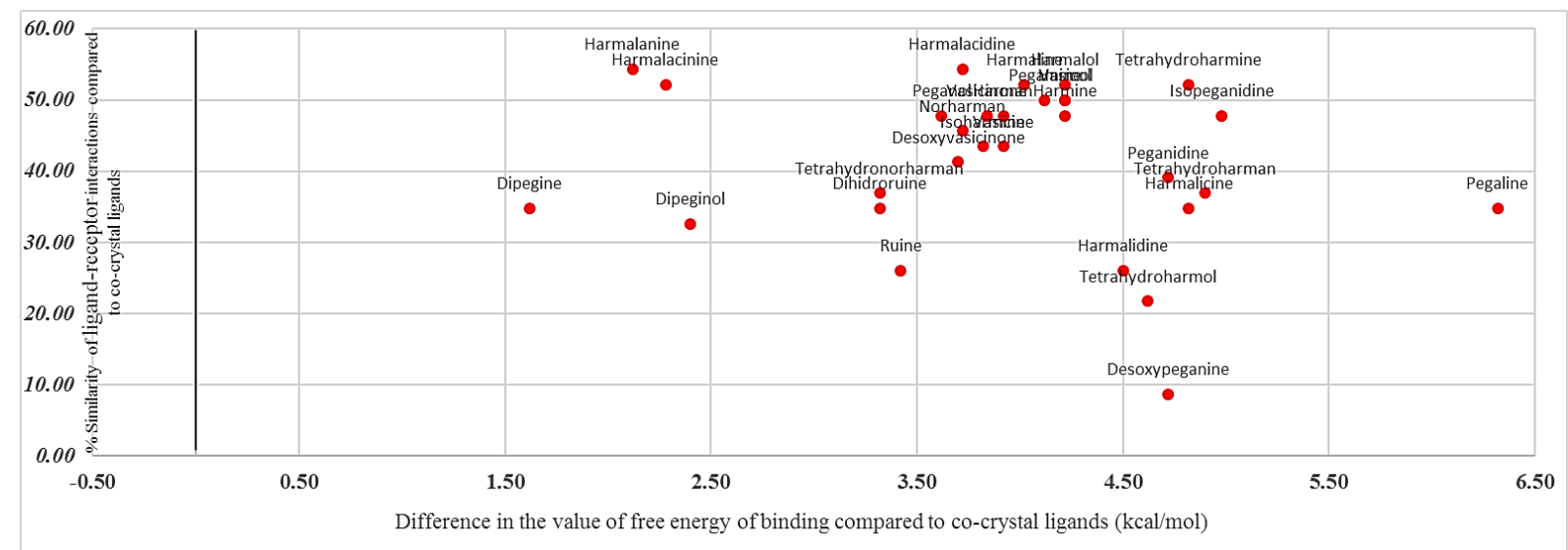

Figure 8. Diagram of the relationship between the difference in the value of free energy of binding and the percentage of similarity of ligand-receptor interactions compared to reference ligands on the 6CM4 receptor.

In contrast to that shown by risperidone, the interactions shown by harmalanine (8) and harmalacinine (7) tend to have many high-energy interactions, such as more hydrogen bonds. The two ligands also have interactions with key amino acids from 6CM4 receptors, such as 
cysteine 118 and serine 197. Uniquely, the two ligands show higher $\Delta \mathrm{G}$ values than dipegine (4), which do not show any interactions with these two key amino acids. The number of interactions with the amino acid residues of dipegine (4) is also less than the two ligands. In fact, both in terms of interacting amino acids and types of interactions that occur from dipegine (4), it is not much different from other test ligands. This shows that there are steric factors that provide an advantage in the interaction between dipegine (4) and the binding site of DRD2 [32].

Unlike harmalanine (8) and harmalacinine (7), dipegine (4) exhibits a relatively similar ratio of interaction types to risperidone, albeit in smaller amounts. After being first reported on $P$. harmala by Faskhutdinov et al., studies related to dipegine (4) itself have been relatively rare [33]. Another study by Shakhidoyatov \& Elmuradov that specifically discussed the various potential activities of some quinazoline alkaloids also did not report the potential activity of dipegine (4) [34]. Therefore, the results of this study open up exploration opportunities for dipegine to be developed as a DRD2 antagonist, including for use in schizophrenia therapy. However, there are still other points that must be considered, particularly the relatively low ligand-receptor similarity compared to risperidone as the reference ligand. This is a concern because there is a possibility that the affinity of dipegine (4) to DRD2 not as an antagonist [35, 36]. Further research with molecular dynamic simulation can be performed to confirm it [37]. It is also important to compare ligand-receptor interactions between dipegine (4) and other reference ligands, which often function as DRD2 antagonists since it is probable that the dipegine-DRD2 interaction does not mimic risperidone but resembles other ligands of comparable behavior [38].

Similar to dipegine (4), harmalanine (8) and harmalacinine (7) also showed a higher $\Delta \mathrm{G}$ than risperidone. The difference is that both harmalanine (8) and harmalacinine (7) show higher ligand-receptor similarity to risperidone, which is more than $50 \%$. Considering the shape, size, and pharmacophore profile that differ significantly between risperidone and the two, a similarity of more than $50 \%$ is sufficient to say that it is high [39]. Thus, there is a chance that both harmalanine (8) and harmalacinine (7) could provide a similar activity to risperidone as a DRD2 antagonist, of course, taking into account other parameters such as ADMET properties. These results are consistent with previous studies that reported that alkaloids from $P$. harmala are known to have activity against CNS, including dopamine receptor antagonists [40-42]. However, the potential shown by both of them is still lower than that of risperidone. In order to improve the efficacy of both, it is possible to modify the structure of various pharmacophores of harmalanine (8) and harmalacinine (7) [43].

Overall, this study reveals that while certain $P$. harmala alkaloids have the potential to develop as DRD2 antagonists, development is required to improve their potency. This research also has some limitations; not all $P$. harmala alkaloids have been reported to be included in the study. The approach used is limited to predictions and has to be retested experimentally in vitro [44]. Further research of ADMET analysis and molecular dynamic simulation of the three potential ligands can be performed to provide more comprehensive information prior to starting in vitro testing.

\section{Conclusions}

This study shows that among other alkaloids from $P$. harmala, dipegine, harmalanine, and harmalacine show the potential to be developed as DRD2 antagonists. Although the potential shown by the three is still lower than risperidone, the difference is not too large. The 
modification of the chemical structure of the compound is expected to increase its potential as a DRD2 antagonist. Further research can be done by conducting an ADMET analysis of $P$. harmala alkaloids, in particular those that show potential as DRD2 antagonists.

\section{Funding}

This research received no external funding.

\section{Acknowledgments}

The author thanked the Chancellor of Universitas Muhammadiyah Palangkaraya and Azerbaijan Medical University for facilitating the administration of this research.

\section{Conflicts of Interest}

The authors declare no conflict of interest.

\section{References}

1. Wang, Z.; Kang, D.; Jia, X.; Zhang, H.; Guo, J.; Liu, C.; Meng, Q.; Liu, W. Analysis of alkaloids from Peganum harmala L. sequential extracts by liquid chromatography coupled to ion mobility spectrometry. $J$. Chromatogr. B 2018, 1096, 73-79, https://doi.org/10.1016/j.jchromb.2018.08.021.

2. Sheahan, M.C.; Chase, M.W. A phylogenetic analysis of Zygophyllaceae R. Br. based on morphological anatomical and rbcL DNA sequence data. Bot. J. Linn. Soc. 1996, 122, 279-300, https://doi.org/10.1111/j.1095-8339.1996.tb02077.x.

3. Woutersen, A.; Jardine, P.E.; Bogotá-Angel, R.G.; Hong-Xiang, Z.; Silvestro, D.; Antonelli, A.; Gogna, E.; Erkens, R.; Gosling, W.D.; Dupont-Nivet, G.; Hoorn, C. A novel approach to study the morphology and chemistry of pollen in a phylogenetic context, applied to the halophytic taxon Nitraria L. (Nitrariaceae). PeerJ 2018, 6, https://doi.org/10.7717/peerj.5055.

4. Li, S.; Cheng, X.; Wang, C. A review on traditional uses, phytochemistry, pharmacology, pharmacokinetics and toxicology of the genus Peganum. J. Ethnopharmacol. 2017, 203, 127-162, https://doi.org/10.1016/j.jep.2017.03.049.

5. Mamedov, N.; Pasdaran, A.; Mamadalieva, N. Pharmacological studies of Syrian rue (Peganum harmala L., Zygophyllaceae). Int. J. Second. Metab. 2018, 5, 1-6, https://doi.org/10.21448/ijsm.335539.

6. Djamshidian, A.; Bernschneider-Reif, S.; Poewe, W.; Lees, A.J. Banisteriopsis caapi, a forgotten potential therapy for Parkinson's disease? Mov. Disord. Clin. Pract. 2016, 3, 19-26, https://doi.org/10.1002/mdc3.12242.

7. Moloudizargari, M.; Mikaili, P.; Aghajanshakeri, S.; Asghari, M.H.; Shayegh, J. Pharmacological and therapeutic effects of Peganum harmala and its main alkaloids. Pharmacogn. Rev. 2013, 7, 199-212, https://doi.org/10.4103/0973-7847.120524.

8. Vahabzadeh, M.; Mohammadi, A.B.; Delirrad, M. Abortion induced by Peganum harmala ingestion in a pregnant woman; a case report and literature review. Int. J. Med. Toxicol. Forensic Med. 2019, 9, 165-170.

9. Carli, M.; Kolachalam, S.; Aringhieri, S.; Rossi, M.; Giovannini, L.; Maggio, R.; Scarselli, M. Dopamine D2 Receptors Dimers: How can we Pharmacologically Target Them? Curr. Neuropharmacol. 2018, 16, 222230, https://dx.doi.org/10.2174/1570159X15666170518151127.

10. de Oliveira, P.G.; Ramos, M.L.S.; Amaro, A.J.; Dias, R.A.; Vieira, S.I. G $\mathrm{i}_{\mathrm{i} / \mathrm{o}}$-Protein Coupled Receptors in the Aging Brain. Front. Aging Neurosci. 2019, 11, https://dx.doi.org/10.3389/fnagi.2019.00089.

11. Pan, X.; Kaminga, A.C.; Wen, S.W.; Wu, X.; Acheampong, K.; Liu, A. Dopamine and Dopamine Receptors in Alzheimer's Disease: A Systematic Review and Network Meta-Analysis. Front. Aging Neurosci. 2019, 11, https://dx.doi.org/10.3389/fnagi.2019.00175.

12. Martorana, A.; Koch, G. Is dopamine involved in Alzheimer's disease? Front. Aging Neurosci. 2014, 6, https://dx.doi.org/10.3389/fnagi.2014.00252.

13. Iarkov, A.; Barreto, G.E.; Grizzell, J.A.; Echeverria, V. Strategies for the Treatment of Parkinson's Disease: Beyond Dopamine. Front. Aging Neurosci. 2020, 12, https://dx.doi.org/10.3389/fnagi.2020.00004.

14. Emamzadeh, F.N.; Surguchov, A. Parkinson's Disease: Biomarkers, Treatment, and Risk Factors. Front. Neurosci. 2018, 12, https://dx.doi.org/10.3389/fnins.2018.00612.

15. Stępnicki, P.; Kondej, M.; Kaczor, A.A. Current Concepts and Treatments of Schizophrenia. Molecules 2018, 23, https://dx.doi.org/10.3390/molecules23082087. 
16. Wang, S.; Che, T.; Levit, A.; Shoichet, B.K.; Wacker, D.; Roth, B.L. Structure of the D2 dopamine receptor bound to the atypical antipsychotic drug risperidone. Nature 2018, 555, 269-273, https://doi.org/10.1038/nature25758.

17. Rampino, A.; Marakhovskaia, A.; Soares-Silva, T.; Torretta, S.; Veneziani, F.; Beaulieu, J.M. Antipsychotic Drug Responsiveness and Dopamine Receptor Signaling; Old Players and New Prospects. Front. Psychiatry 2018, 9, https://dx.doi.org/10.3389/fpsyt.2018.00702.

18. Pratama, M.R.F.; Poerwono, H.; Siswodihardjo, S. Molecular docking of novel 5-O-benzoylpinostrobin derivatives as wild type and L858R/T790M/V948R mutant EGFR inhibitor. J. Basic Clin. Physiol. Pharmacol. 2019, 30, https://doi.org/10.1515/jbcpp-2019-0301.

19. Pratama, M.R.F.; Poerwono, H.; Siswandono, S. Design and Molecular Docking of Novel 5-OBenzoylpinostrobin Derivatives as Anti-Breast Cancer. Thai J. Pharm. Sci. 2019, 43, 201-212.

20. Ramirez, D.; Caballero, J. Is It Reliable to Take the Molecular Docking Top Scoring Position as the Best Solution without Considering Available Structural Data? Molecules 2018, 23, https://doi.org/10.3390/molecules23051038.

21. Hassan, N.M.; Alhossary, A.A.; Mu, Y.; Kwoh, C.K. Protein-Ligand Blind Docking Using QuickVina-W With Inter-Process Spatio-Temporal Integration. Sci. Rep. 2017, 7, https://doi.org/10.1038/s41598-01715571-7.

22. Macari, G.; Toti, D.; Moro, C.D.; Polticelli, F. Fragment-Based Ligand-Protein Contact Statistics: Application to Docking Simulations. Int. J. Mol. Sci. 2019, 20, https://doi.org/10.3390/ijms20102499.

23. Trott, O.; Olson, A.J. AutoDock Vina: improving the speed and accuracy of docking with a new scoring function, efficient optimization and multithreading. J. Comput. Chem. 2010, 31, 455-461, https://dx.doi.org/10.1002/jcc.21334.

24. Gaillard, T. Evaluation of AutoDock and AutoDock Vina on the CASF-2013 Benchmark. J. Chem. Inf. Model. 2018, 58, 1697-1706, https://doi.org/10.1021/acs.jcim.8b00312.

25. Vieira, T.F.; Sousa, S.F. Comparing AutoDock and Vina in Ligand/Decoy Discrimination for Virtual Screening. Appl. Sci. 2019, 9, https://doi.org/10.3390/app9214538.

26. Ding, Y.; Fang, Y.; Moreno, J.; Ramanujam, J.; Jarrell, M.; Brylinski, M. Assessing the similarity of ligand binding conformations with the Contact Mode Score. Comput. Biol. Chem. 2016, 64, 403-413, https://dx.doi.org/10.1016/j.compbiolchem.2016.08.007.

27. Pratama, M.R.F.; Mulyani, E.; Suratno, S. Molecular Docking Study of Akar Kuning (Arcangelisia flava) Secondary Metabolites as Src Inhibitor. Indones. J. Cancer Chemoprevention 2019, 10, 122-130, http://dx.doi.org/10.14499/indonesianjcanchemoprev10iss3pp122-130.

28. Zhou, H.X.; Pang, X. Electrostatic Interactions in Protein Structure, Folding, Binding, and Condensation. Chem. Rev. 2018, 118, 1691-1741, https://dx.doi.org/10.1021/acs.chemrev.7b00305.

29. Du, X.; Li, Y.; Xia, Y.L.; Ai, S.M.; Liang, J.; Sang, P.; Ji, X.L.; Liu, S.Q. Insights into Protein-Ligand Interactions: Mechanisms, Models, and Methods. Int. J. Mol. Sci. 2016, 17, https://dx.doi.org/10.3390/ijms17020144.

30. Kastritis, P.L.; Bonvin, A.M.J.J. On the binding affinity of macromolecular interactions: daring to ask why proteins interact. J. R. Soc. Interface 2013, 10, https://dx.doi.org/10.1098/rsif.2012.0835.

31. Shimizu, K.; da Silva, J.F. Halogen and Hydrogen Bonding Interplay in the Crystal Packing of Halometallocenes. Molecules 2018, 23, https://dx.doi.org/10.3390/molecules23112959.

32. Schneider, M.; Pons, J.L.; Bourguet, W.; Labesse, G. Towards accurate high-throughput ligand affinity prediction by exploiting structural ensembles, docking metrics and ligand similarity. Bioinformatics 2020, 36, 160-168, https://doi.org/10.1093/bioinformatics/btz538.

33. Faskhutdinov, M.F.; Telezhenetskaya, M.V.; Levkovich, M.G.; Abdullaev, N.D. Alkaloids of Peganum harmala. Chem. Nat. Compd. 2000, 36, 602-605, https://doi.org/10.1023/A:1017524027513.

34. Shakhidoyatov, K.M.; Elmuradov, B.Z. Tricyclic Quinazoline Alkaloids: Isolation, Synthesis, Chemical Modification, and Biological Activity. Chem. Nat. Compd. 2014, 50, 781-800, https://doi.org/10.1007/s10600-014-1086-6.

35. Williams, M.; Raddatz, R.; Mehlin, C.; Triggle, D.J. Receptor Targets in Drug Discovery. In: Reviews in Cell Biology and Molecular Medicine. Wiley-VCH Verlag GmbH \& Co. KGaA.: Weinheim, Germany, Volume Supplement 10, 2006; pp. 593-636, https://doi.org/10.1002/3527600906.mcb.200500063.

36. Kim, S.K.; Gao, Z.G.; Jeong, L.S.; Jacobson, K.A. Docking studies of agonists and antagonists suggest an activation pathway of the A3 adenosine receptor. J. Mol. Graph. Model. 2006, 25, 562-577, http://doi.org/10.1016/j.jmgm.2006.05.004.

37. Salmaso, V.; Moro, S. Bridging Molecular Docking to Molecular Dynamics in Exploring Ligand-Protein Recognition Process: An Overview. Front. Pharmacol. 2018, https://dx.doi.org/10.3389/fphar.2018.00923.

38. Salahudeen, M.S.; Nishtala, P.S. An overview of pharmacodynamic modelling, ligand-binding approach and its application in clinical practice. Saudi Pharm. J. 2017, 25, 165-175, https://dx.doi.org/10.1016/j.jsps.2016.07.002.

39. Sliwoski, G.; Kothiwale, S.; Meiler, J.; Lowe, E.W. Computational Methods in Drug Discovery. Pharmacol. Rev. 2014, 66, 334-395, https://dx.doi.org/10.1124/pr.112.007336. 
40. Siddiqui, S.; Khan, O.Y.; Faizi, S.; Siddiqui, B.S. Studies in the Chemical Constituents of the Seeds of Pegnum harmala: Isolation and Structure Elucidation of Two $\beta$-Carboline Lactams - Harmalanine and Harmalacidine. Heterocycles 1988, 27, 1401-1410, https://doi.org/10.3987/COM-88-4490.

41. Moloudizargari, M.; Mikaili, P.; Aghajanshakeri, S.; Asghari, M.H.; Shayegh, J. Pharmacological and Therapeutic Effects of Peganum harmala and its Main Alkaloids. Pharmacogn. Rev. 2013, 7, 199-212, http://dx.doi.org/10.4103/0973-7847.120524.

42. Wang, K.B.; Li, D.H.; Bao, Y.; Cao, F.; Wang, W.J.; Lin, C.; Bin, W.; Bai, J.; Pei, Y.H.; Jing, Y.K.; Yang, D.; Li, Z.L.; Hua, H.M. Structurally Diverse Alkaloids from the Seeds of Peganum harmala. J. Nat. Prod. 2017, 80, 551-559, https://doi.org/10.1021/acs.jnatprod.6b01146.

43. Hughes, J.P.; Rees, S.; Kalindjian, S.B.; Philpott, K.L. Principles of early drug discovery. Br. J. Pharmacol. 2011, 162, 1239-1249, https://dx.doi.org/10.1111/j.1476-5381.2010.01127.x.

44. Alberca, L.N.;Chuguransky, S.R.; Alvarez, C.L.; Talevi, A.; Salas-Sarduy, E. In silico Guided Drug Repurposing: Discovery of New Competitive and Non-competitive Inhibitors of Falcipain-2. Front. Chem. 2019, 7, 534, https://dx.doi.org/10.3389/fchem.2019.00534 